UNIVERSIDADE DE BRASÍLIA

FACULDADE DE CIÊNCIAS DA SAÚDE

DEPARTAMENTO DE ENFERMAGEM

PROGRAMA DE PÓS-GRADUAÇÃO EM ENFERMAGEM

TALITA FARAJ FARIA

COMPLICAÇÕES DE ESTOMIAS EM CRIANÇAS: FREQUÊNCIA E FATORES ASSOCIADOS

BRASÍLIA-DF 


\author{
UNIVERSIDADE DE BRASÍLIA \\ FACULDADE DE CIÊNCIAS DA SAÚDE \\ DEPARTAMENTO DE ENFERMAGEM \\ PROGRAMA DE PÓS-GRADUAÇÃO EM ENFERMAGEM
}

TALITA FARAJ FARIA

\title{
COMPLICAÇÕES DE ESTOMIAS EM CRIANÇAS: FREQUÊNCIA E FATORES ASSOCIADOS
}

Dissertação apresentada ao Programa de Pósgraduação em Enfermagem, da Universidade de Brasília, como requisito parcial para a obtenção do título de Mestre em Enfermagem.

Área de concentração: Cuidado, Gestão e Tecnologias em Saúde e Enfermagem

Linha de pesquisa: Processo de cuidar em saúde e enfermagem

Tema de pesquisa: Enfermagem em Estomaterapia

Orientadora: Ivone Kamada

BRASÍLIA-DF 
Ficha catalográfica elaborada automaticamente, com os dados fornecidos pelo(a) autor(a)

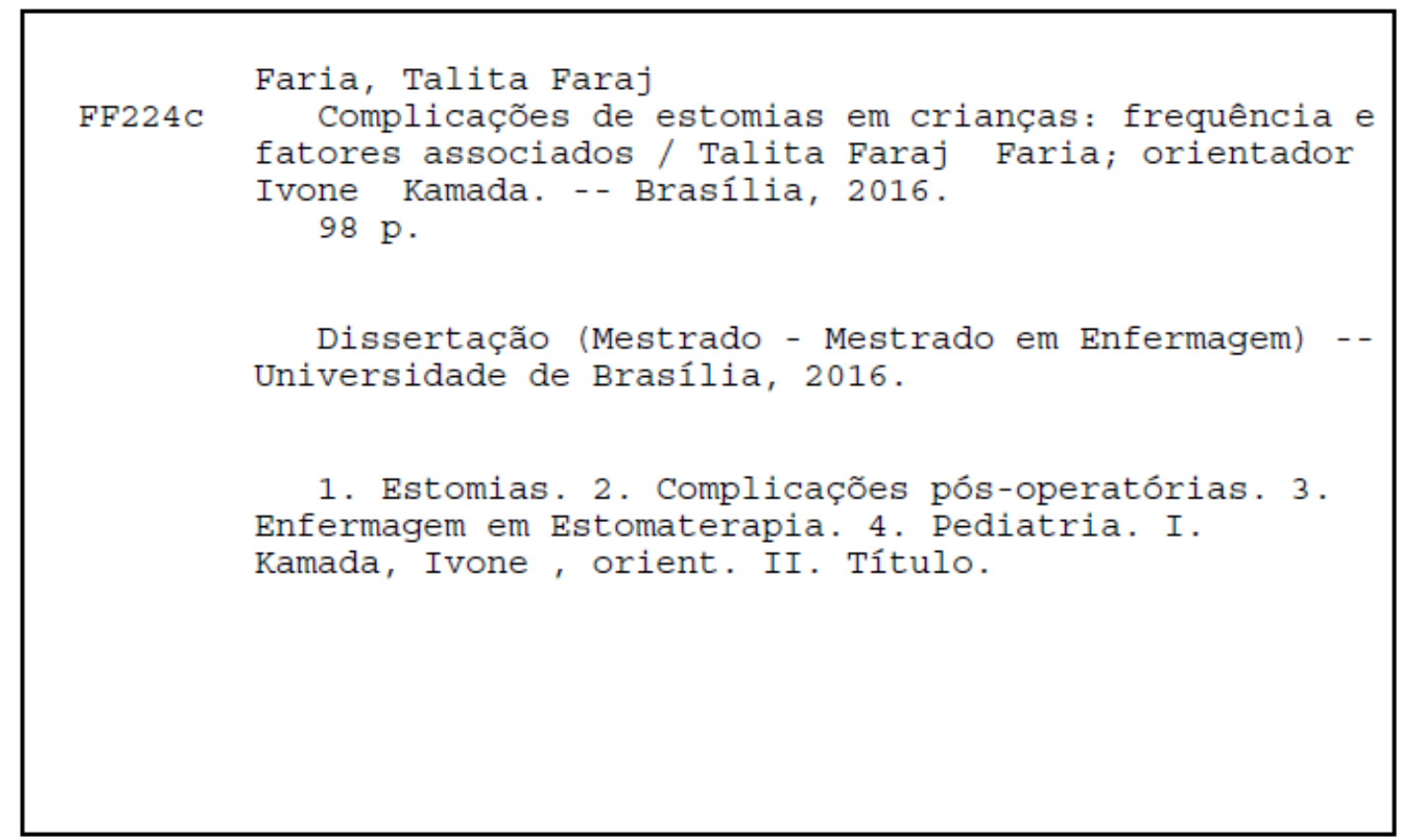




\section{COMPLICAÇÕES DE ESTOMIAS EM CRIANÇAS: FREQUÊNCIA E FATORES} ASSOCIADOS

Dissertação apresentada ao Programa de Pósgraduação em Enfermagem, da Universidade de Brasília, como requisito parcial para a obtenção do título de Mestre em Enfermagem.

Aprovado em 16 de dezembro de 2016.

BANCA EXAMINADORA

Professora Doutora Ivone Kamada

Presidente da banca

Universidade de Brasília

Professora Doutora Cristine Alves Costa de Jesus

Membro efetivo

Universidade de Brasília

Professora Doutora Ana Beatriz Duarte Vieira

Membro efetivo, externo ao Programa

Universidade de Brasília

Professora Doutora Ana Lúcia da Silva

Membro Suplente, externo ao Programa

Universidade de Brasília 
Dedico este trabalho às crianças com estomias, seus familiares e profissionais de saúde envolvidos no cuidado a estas pessoas tão especiais. 


\section{AGRADECIMENTOS}

À minha família, pelo carinho, pelos conselhos, incentivo e apoio às minhas escolhas ao longo dos anos, torcendo sempre pelo meu êxito e me incentivando a buscar o conhecimento e a evolução como ser humano e profissional de saúde.

À minha orientadora, professora Dra. Ivone Kamada, por me acompanhar desde a graduação e acolher minhas ideias e projetos, pelo constante incentivo a realizar pesquisas na área da Estomaterapia, pelas orientações dadas para construção deste estudo e contribuição para a minha evolução profissional.

À professora Dra. Ana Lúcia da Silva, por transmitir seus conhecimentos em Estomaterapia e sempre incentivar a busca pelo conhecimento e o desenvolvimento de estudos na área.

Às professoras Dra. Cristine Alves Costa de Jesus e Dra. Ana Beatriz Duarte Vieira, por aceitarem fazer parte da banca examinadora.

Aos professores do Programa de Pós-graduação em Enfermagem da Universidade de Brasília, pelo conhecimento compartilhado e que serviu de base para a execução deste estudo.

À equipe de Enfermagem do ambulatório de Atenção ao Estomizado do hospital escolhido para realização do estudo, por me receberem com respeito e paciência, permitindo que meu estudo fosse realizado no setor.

Aos amigos enfermeiros Rafael, Anna Kristina, Jarine e Juliana Gracielle pelo apoio desde o final da graduação e durante o mestrado. Serei eternamente grata pelo carinho e palavras de incentivo.

À enfermeira Fátima Sicca, pela amizade e suporte desde a minha graduação, pelo exemplo de competência profissional e por despertar em mim o desejo de aprimorar cada vez mais meus estudos na área de Estomaterapia e Dermatologia.

À Coordenação de Apoio à Pesquisa e Ensino Superior (CAPES), pela concessão da bolsa de mestrado acadêmico durante o desenvolvimento desta pesquisa.

A todos aqueles que contribuíram indireta ou diretamente para a construção, desenvolvimento e conclusão desta pesquisa. 
"Mestre não é quem sempre ensina, mas quem de repente aprende".

Guimarães Rosa 


\section{RESUMO}

FARIA, T.F. Complicações de estomias em crianças: frequência e fatores associados. 2016. 98 p. Dissertação de Mestrado. Departamento de Enfermagem, Faculdade de Ciências da Saúde, Universidade de Brasília. Brasília, Distrito Federal, 2016.

O processo de confecção da estomia na criança gera impacto em seu cotidiano e no de seus familiares, pois afeta sua integridade corporal, assim como seu convívio social e sua qualidade de vida. Apesar de a confecção do estoma ser considerada um procedimento cirúrgico simples, geralmente surgem complicações que na maioria das vezes podem ser evitadas. Objetivo: Estudar a ocorrência de complicações de estomias em crianças, caracterizar o perfil sociodemográfico e clínico das crianças atendidas no ambulatório, verificar a incidência destas complicações, assim como o tipo de complicações existentes no estoma e pele periestoma das crianças, além do tratamento empregado para resolução do problema. Método: Trata-se de um estudo quantitativo, descritivo, de caráter prospectivo, realizado com 37 crianças no período de fevereiro a agosto de 2016 no ambulatório de um hospital público de Brasília. Para a análise estatística foi utilizado o programa Statistical Package for the Social Sciences ${ }^{\circledR}$ (SPSS), versão 23.0, onde as variáveis categóricas foram descritas por meio de frequência absoluta e relativa e as variáveis quantitativas por meio da média e desvio padrão. O teste exato de Fisher e o teste qui-quadrado foram utilizados para comparar associações entre variáveis qualitativas. Resultados: Das crianças estudadas, 56,7\% apresentaram complicações relacionadas às estomias, totalizando 25 complicações observadas durante a coleta de dados, sendo que algumas das crianças apresentaram mais de um tipo de complicação. A complicação mais frequente foi a dermatite de contato (76\% dos casos). Conclusão: Espera-se que os dados obtidos a partir desta pesquisa possam ser utilizados para melhorar o atendimento das crianças estomizadas, subsidiando o planejamento das ações dos profissionais de saúde, a fim de evitar e/ou diminuir a ocorrência das complicações.

Descritores: Estomia; Complicações Pós-operatórias; Recém-nascido; Lactente; Pré-escolar; Criança. 


\begin{abstract}
FARIA, T.F. Ostomy complications in children: frequency and associated factors. 2016. 98 p. Master's dissertation. Nursing Department, College of Health Sciences, University of Brasilia. Brasilia, Federal District, 2016.
\end{abstract}

The process involved on ostomy surgery in children generates an impact on their daily lives and their families, it affects their physical integrity as well as their social life and their quality of life. Despite the ostomy production being considered a simple surgical procedure, complications can arise which, in most cases, can be avoided. Objective: Study the incidence of ostomy complications in children, characterize the sociodemographic and clinical profiles in children seen by the clinic, check the incidence of such implications as well as the type of existing complications in the ostomy and peristomal skin of these children in addition to the treatment employed to solve the problem. Method: This is a quantitative, descriptive, prospective character study performed with 37 children between the periods of February to August 2016 at a clinic of a public hospital in Brasília. For the statistical analysis, the program Statistical Package for the Social Sciences ${ }^{\circledR}$ (SPSS) version 23.0 was used to determine where the categorical variables were described by absolute and relative frequencies and the quantitative variables were described by means of average and standard deviation. The exact Fisher test and the chi-square test were used to compare associations between qualitative variables. Results: From the studied children, 56,7\% had ostomy complications, totaling 25 complications during the data collection, and some of the children presented more than one type of complication. The most frequent complication was contact dermatitis $(76 \%)$. Conclusion: It is expected that the data obtained from this research can be used to improve the care of ostomized children, subsidizing action planning on behalf of health professionals to avoid and/or reduce the complications incidence.

Keywords: Ostomy; Postoperative Complications; Newborn; Infant; Child, Preschool; Child. 


\section{RESUMEN}

FARIA, T.F. Complicações de estomias em crianças: frequência e fatores associados. 2016. 98 p. Tesis de Maestría. Departamento de Enfermería, Facultad de Ciencias de la Salud, Universidad de Brasilia. Brasilia, Distrito Federal, 2016.

El proceso de confección de la ostomía en el niño genera impacto en su cotidiano y en el cotidiano de sus familiares, ya que afecta su integridad corporal, así como su convivio social y su calidad de vida. Aunque se considere la confección del ostoma como un procedimiento quirúrgico simple, generalmente surgen complicaciones que en la mayoría de las veces se pueden evitar. Objetivo: Estudiar la ocurrencia de las complicaciones de ostomías en niños, caracterizar el perfil sociodemográfico y clínico de los niños atendidos en el ambulatorio, verificar la incidencia de estas complicaciones, así como el tipo de complicaciones que existen en el estoma y piel periestoma de los niños, además del tratamiento que se emplea para la resolución del problema. Método: Se trata de un estudio cuantitativo, descriptivo, de carácter prospectivo, realizado entre 37 niños en el periodo de febrero a agosto de 2016 en un ambulatorio de un hospital de la red pública de Brasilia. Para el análisis estadístico se utilizó el programa Statistical Package for the Social Sciences ${ }^{\circledR}$ (SPSS), versión 23.0, donde se describieron las variables categóricas por medio de frecuencia absoluta y relativa y las variables cuantitativas por medio del promedio y desvío estándar. Se utilizaron el test exacto de Fisher y el test chi cuadrado para comparar asociaciones entre variables cuantitativas. Resultados: De los niños estudiados, el 56,7\% presentaron complicaciones relacionadas a las ostomías, totalizando 25 complicaciones observadas durante la colecta de datos, siendo que algunos de los niños presentaron más de un tipo de complicación. La complicación más frecuente fue dermatitis de contacto $(76 \%)$. Conclusión: Se espera que se puedan utilizar los datos obtenidos a partir de esta pesquisa para mejorar el atendimiento a los niños ostomizados, subsidiando la planificación de las acciones de los profesionales de salud, a fin de evitar y/o disminuir la ocurrencia de las complicaciones.

Palabras clave: Estomía; Complicaciones Posoperatorias; Recién nacido; Lactante; Preescolar; Niño. 


\section{LISTA DE FIGURAS}

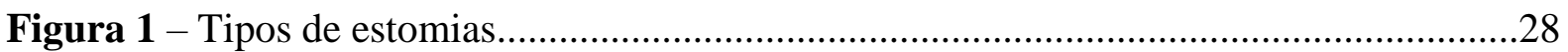

Figura 2 - Principais acidentes anatômicos a serem considerados na demarcação das

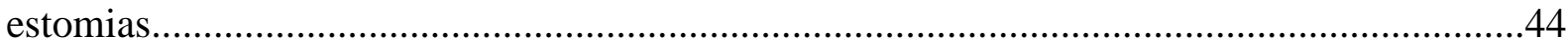




\section{LISTA DE QUADROS}

Quadro 1 - Indicação de traqueostomia na população pediátrica.........................................30

Quadro 2 - Contraindicações específicas da técnica de confecção da gastrostomia por via endoscópica.

Quadro 3 - Classificação das publicações selecionadas para compor a revisão integrativa da literatura quando ao ano, autor e título.

Quadro 4 - Classificação das publicações segundo o objetivo, tipo de estudo, Qualis CAPES e nível de evidência. 


\section{LISTA DE GRÁFICOS}

Gráfico 1 - Distribuição dos diagnósticos médicos das crianças com estomias atendidas no ambulatório.

Gráfico 2 - Frequência absoluta das estomias de acordo com a localização. .63 


\section{LISTA DE TABELAS}

Tabela 1 - Distribuição das características sociodemográficas das crianças estomizadas de acordo com o sexo, idade, procedência e escolaridade.

Tabela 2 - Medidas e valores das características das crianças segundo a idade, tempo de permanência da estomia e número de consultas de enfermagem.

Tabela 3 - Tempo de permanência das estomias nas crianças assistidas no ambulatório.... .64

Tabela 4 - Tipos de complicações de estomias nas crianças estudadas.

Tabela 5 - Associação entre o sexo das crianças e a ocorrência de complicação.

Tabela 6 - Associação entre orientação prévia sobre a confecção da estomia e a ocorrência de complicação .66

Tabela 7 - Associação entre demarcação prévia da estomia e a ocorrência de complicação..... .66

Tabela 8 - Associação entre utilização de equipamento coletor e a ocorrência de complicação. .66 


\section{LISTA DE SIGLAS}

AOSDF

CEP

DECS

DF

DIP

FEPECS

HRAS

HUB

MESH

NEPS

PEAC

PO

RIL

$\mathrm{RN}$

RR

SAEE

SES-DF

SNC

SOBEST

TCC

TCLE
Associação dos Ostomizados do Distrito Federal

Comitê de Ética em Pesquisa

Descritores em Ciências da Saúde

Distrito Federal

Doenças infecto-parasitárias

Fundação de Ensino e Pesquisa em Ciências da Saúde

Hospital Regional da Asa Sul

Hospital Universitário de Brasília

Medical Subject Headings

Núcleo de Educação e Pesquisa em Saúde

Projeto de Extensão de Ação Contínua

Pós-Operatório

Revisão Integrativa da Literatura

Recém-nascido

Risco Relativo

Serviço Ambulatorial de Enfermagem em Estomaterapia

Secretaria de Estado de Saúde do Distrito Federal

Sistema Nervoso Central

Associação Brasileira de Estomaterapia

Trabalho de Conclusão de Curso

Termo de Consentimento Livre e Esclarecido 


\section{LISTA DE SÍMBOLOS}

Fr

French

$\mathrm{cm}$

centímetros

$\mathrm{mL}$

mililitros 


\section{SUMÁRIO}

1. APRESENTAÇÃOO

2. INTRODUÇÃO

2.1 CONSIDERAÇÕES INICIAIS

2.2 JUSTIFICATIVA DO ESTUDO 24

3. OBJETIVOS

3.1 GERAL 26

3.2 ESPECÍFICOS 26

4. REVISÃO DA LITERATURA

4.1 CLASSIFICAÇÃO DAS ESTOMIAS

4.2 PROCEDIMENTO DE DEMARCAÇÃO DAS ESTOMIAS 43

4.3 COMPLICAÇÕES DE ESTOMIAS

4.4 REVISÃO BIBLIOGRÁFICA

5. MATERIAIS E MÉTODO

5.1 TIPO DE ESTUDO

5.2 LOCAL DO ESTUDO

5.3 POPULAÇÃO E AMOSTRA

5.4 COLETA DE DADOS

5.5 ANÁLISE E CATEGORIZAÇÃO DOS DADOS

5.6 ASPECTOS ÉTICOS E LEGAIS

5.7 DESCRIÇÃO DO ESTUDO

6. RESULTADOS

6.1 PERFIL SOCIODEMOGRÁFICO E CLÍNICO DAS CRIANÇAS COM ESTOMIAS 61

6.2 CARACTERÍSTICAS DAS ESTOMIAS DAS CRIANÇAS ATENDIDAS NO AMBULATÓRIO 63

6.3 COMPLICAÇÕES DE ESTOMIAS E OS FATORES ASSOCIADOS 64

7. DISCUSSÃO $\quad 68$

8. CONCLUSÃO

9. REFERÊNCIAS

\begin{tabular}{lr} 
APÊNDICE & 89 \\
\hline
\end{tabular}

$\begin{array}{ll}\text { APÊNDICE A } & 89\end{array}$

\begin{tabular}{ll} 
ANEXOS & 91 \\
\hline
\end{tabular}

$\begin{array}{ll}\text { ANEXO A } & 91\end{array}$

ANEXO B $\quad 93$

$\begin{array}{ll}\text { ANEXO C } & 95\end{array}$ 
Apresentação 


\section{APRESENTAÇÃO}

Ingressei no curso de Enfermagem da Universidade de Brasília (UnB), no ano de 2010, após desistir do curso de letras (o qual também cursava na UnB, campus Darcy Ribeiro), influenciada pelo cuidado que prestava aos meus avós paternos há alguns anos com ajuda da minha irmã.

O interesse em pesquisar na área de Estomaterapia surgiu ainda na graduação, quando tive a oportunidade de fazer parte do Projeto de Extensão de Ação Contínua intitulado "Serviço Ambulatorial de Enfermagem em Estomaterapia" (PEAC-SAEE), onde permaneci como acadêmica extensionista do sexto até o décimo semestre.

O referido projeto de extensão foi criado em 1999 e proporciona aos acadêmicos de Enfermagem, a partir do $5^{\circ}$ semestre de graduação, a experiência de prestar cuidados ambulatoriais aos indivíduos com feridas, estomias e incontinências no Hospital Universitário de Brasília (HUB), assim como participar de reuniões científicas promovidas pela Associação Brasileira de Estomaterapia (SOBEST) que abordam diversos assuntos relacionados à área em questão, além de reuniões com os estomizados organizadas mensalmente pela Associação dos Ostomizados do Distrito Federal (AOSDF).

Em 2014, a convite das docentes coordenadoras do PEAC-SAEE, em conjunto com uma colega do projeto (Simone Silva dos Santos), fui designada para realizar o treinamento teórico oferecido aos novos e antigos extensionistas, cuja finalidade era apresentar brevemente as atividades desenvolvidas no ambulatório e atualizar o conhecimento destes em relação a temas específicos (troca de equipamento coletor de estomias, coberturas utilizadas para tratamento de feridas, entre outros), visando a segurança e qualidade da assistência prestada (treinamento que sigo realizando até os dias atuais, agora como enfermeira extensionista do projeto). Segui me envolvendo cada vez mais com as atividades do projeto e, no oitavo semestre da graduação, decidi abordar no meu Trabalho de Conclusão de Curso (TCC) um tema que envolvesse a Estomaterapia e a Pediatria, com orientação da professora Ivone Kamada.

No decorrer da minha formação acadêmica fui bolsista do Programa de Iniciação Científica e a convivência com as professoras Ana Lúcia da Silva e Ivone Kamada durante minha participação como extensionista do PEAC-SAEE, assim como as orientações que me foram dadas durante a elaboração do meu TCC foram importantes para que eu decidisse 
ingressar no Mestrado pelo Programa de Pós-graduação em Enfermagem assim que concluísse minha graduação.

Neste contexto, escolhi o Processo de Cuidar em Saúde e Enfermagem como linha de pesquisa e a Enfermagem em Estomaterapia como tema para o mestrado, motivada pelo desejo de aumentar meus conhecimentos e contribuir para a área de Estomaterapia voltada para a população pediátrica, consciente de que poucos estudos abordam esta temática. Deste modo, espero que os resultados aqui apresentados possam subsidiar as ações de enfermagem voltadas para as crianças com estomias e que forneçam informações relevantes para a prática dos profissionais de enfermagem, estimulando também a produção científica acerca da temática pelos enfermeiros envolvidos direta ou indiretamente na assistência a esta clientela. 


\section{Introdução}




\section{INTRODUÇÃO}

\subsection{Considerações iniciais}

A criança é um ser em crescimento e desenvolvimento que necessita de ambiente acolhedor e afeto no ciclo familiar para atendimento de suas necessidades básicas e de aprendizado (MELO, 2010). De acordo com o Estatuto da Criança e do Adolescente, são consideradas crianças todos os indivíduos que tenham até doze anos de idade incompletos, ou seja, 11 anos 11 meses e 29 dias (BRASIL, 1990).

O avanço da tecnologia tem contribuído, ao longo dos anos, para diminuir a mortalidade infantil, permitindo que crianças com diferentes distúrbios fisiológicos sobrevivam. Por outro lado, aumentou-se o número de crianças dependentes de cuidados de saúde e/ou tecnologias, conhecidas como Crianças com Necessidades Especiais de Saúde (CRIANES) (HOCKENBERRY; WILSON, 2011; SILVEIRA; NEVES, 2012).

As CRIANES podem ser divididas em grupos, sendo eles: crianças com demandas de desenvolvimento, como aquelas com disfunção neuromuscular e que necessitam de reabilitação psicomotora e/ou social; crianças com necessidades tecnológicas, como cânula de traqueostomia, equipamentos coletores e cateteres para estomias intestinais e/ou urinárias, entre outros; crianças com necessidades farmacológicas; crianças que dependem de mudanças na forma habitual de cuidado e o grupo misto, com crianças que dependem de uma ou mais destas demandas em conjunto (MORAES; CABRAL, 2012).

Condições como doenças genéticas, anomalias congênitas ou traumas podem evoluir para a confecção de estomas respiratórios, urinários e/ou gastrointestinais em qualquer período da vida. Na população pediátrica, as causas mais comuns que levam à confecção de estomas são anomalias anorretais (por exemplo, imperfuração anal), megacólon congênito, doença de Crohn, enterocolite necrotizante, carcinoma retal, retocolite ulcerativa e polipose adenomatosa familiar (POLETTO et al, 2011). Outras condições que podem levar à confecção de estomias nas crianças são o íleo ou peritonite meconiais, fístula traqueoesofágica, obstrução da traqueia causada por traqueomalácia, traumas, entre outros (KAYO et al, 2015).

Em estudo realizado no estado de São Paulo, $80 \%$ das estomias foram confeccionadas nas primeiras 6 semanas de vida da criança, $10 \%$ entre a sexta semana e o primeiro ano de vida e $10 \%$ das crianças realizaram a cirurgia a partir do primeiro ano de vida. O 
Departamento de Saúde de Nova Iorque, nos EUA, publicou um estudo onde a incidência de estomias foi de 3,4\% nas crianças nascidas com malformações congênitas, sendo mais frequentes em crianças do sexo masculino (3,9\%); das crianças estudadas, 19,4\% apresentaram malformações no sistema urinário, 6,7\% no sistema digestório e 2,6\% no trato respiratório (CARVALHO; SOUZA, 2004 apud GAMBOA 2015; BOSCOLLO et al, 1997 apud GAMBOA, 2015).

De acordo com Valdes e colaboradores (2010), o processo de confecção da estomia na criança gera impacto em seu cotidiano e no de seus familiares, pois afeta sua integridade corporal, assim como sua capacidade funcional, convívio social e, consequentemente, sua qualidade de vida. Além disso, a adaptação ao estoma e o enfrentamento deste processo depende de vários fatores como idade, gênero, estado de saúde, dinâmica familiar, estilo de vida, orientação sociocultural, entre outros (VALDES et al, 2010).

Apesar de a confecção do estoma ser considerada um procedimento cirúrgico simples e que é comumente realizado, geralmente surgem complicações que podem ser evitadas com uma demarcação prévia adequada do local de confecção e com a técnica cirúrgica apropriada (MELO, 2010). De acordo com a Declaração Internacional dos Direitos dos Estomizados, é direito do paciente receber cuidados especializados de enfermagem no pré e no pósoperatório, tanto no hospital quanto em sua comunidade, o que inclui um estoma bem localizado e bem construído (ABRASO, 2007).

O cuidado com o estoma envolve higiene do local, observação das características da estomia e da região periestoma, além da utilização adequada do dispositivo coletor e dos adjuvantes. As complicações relacionadas ao estoma e a região periestoma mais comuns são a dermatite de contato, retração, separação cutaneomucosa, fístula, hérnia paraestomal, prolapso de alça e estenose (YAMADA et al, 2003).

Os estudos de incidência e prevalência de complicações de estomias em crianças, a observação individualizada das crianças acometidas, entre outros, possibilita que seja determinada a extensão do problema nos serviços de saúde, possibilitando a construção de estratégias de prevenção e direcionamento das intervenções dos profissionais de saúde.

Diante do exposto surgiram os seguintes questionamentos: Com que frequência surgem as complicações de estomias em crianças? Quais são as complicações mais incidentes? Quais são os fatores que estão associados ao surgimento destas complicações? 
O presente trabalho teve como objetivo estudar a ocorrência de complicações de estomias em crianças atendidas no ambulatório de um hospital público de referência do Distrito Federal, bem como identificar os tipos de complicações mais frequentes e os fatores associados ao seu surgimento.

\subsection{Justificativa do estudo}

A literatura nacional sobre complicações de estomias em crianças é escassa, revelando a necessidade da elaboração de estudos nesta área. A maior parte dos estudos publicados se referem a população adulta e, na maioria das vezes, não é possível realizar generalizações ou adaptar os resultados para a população pediátrica.

O cuidado da criança com estoma respiratório, urinário e/ou intestinal exige apoio dos profissionais de saúde, principalmente dos enfermeiros, para auxiliar as crianças e/ou os familiares no manejo do estoma e suas possíveis complicações. Deste modo, este estudo justifica-se pela necessidade de se investigar a incidência das complicações relacionadas ao estoma e a pele periestoma na infância, sendo fator importante para o planejamento do cuidado, para a construção de estratégias de prevenção e organização dos serviços de saúde que atendem esta clientela, contribuindo assim para o direcionamento das intervenções de enfermagem e melhora da qualidade de vida das crianças. 
Objetivos 


\section{OBJETIVOS}

\subsection{Geral}

- Estudar a ocorrência de complicações de estomias em crianças atendidas no Ambulatório de Atenção ao Estomizado de um hospital público do Distrito Federal.

\subsection{Específicos}

- Caracterizar o perfil sociodemográfico e clínico das crianças atendidas no Ambulatório de Atenção ao Estomizado de um hospital público do Distrito Federal.

- Verificar a incidência de complicações de estomias nas crianças em seguimento Ambulatório de Atenção ao Estomizado de um hospital público do Distrito Federal.

- Verificar o tipo de complicações existentes no estoma e pele periestoma das crianças atendidas, além do tratamento empregado para resolução do problema. 
Revisão da Literatura 


\section{REVISÃO DA LITERATURA}

\subsection{Classificação das estomias}

Estomias ou estomas são palavras derivadas do grego stóma que significam abertura ou boca, indicando a exteriorização cirúrgica de órgãos ou vísceras, podendo ser classificadas de acordo com sua localização, como por exemplo: traqueostomia quando é confeccionada na traqueia, esofagostomia no esôfago, ileostomia no íleo, colostomia no cólon (intestino grosso), gastrostomia no estômago, cistostomia quando a confecção se dá na bexiga, entre outros (MONTEIRO, 2013).

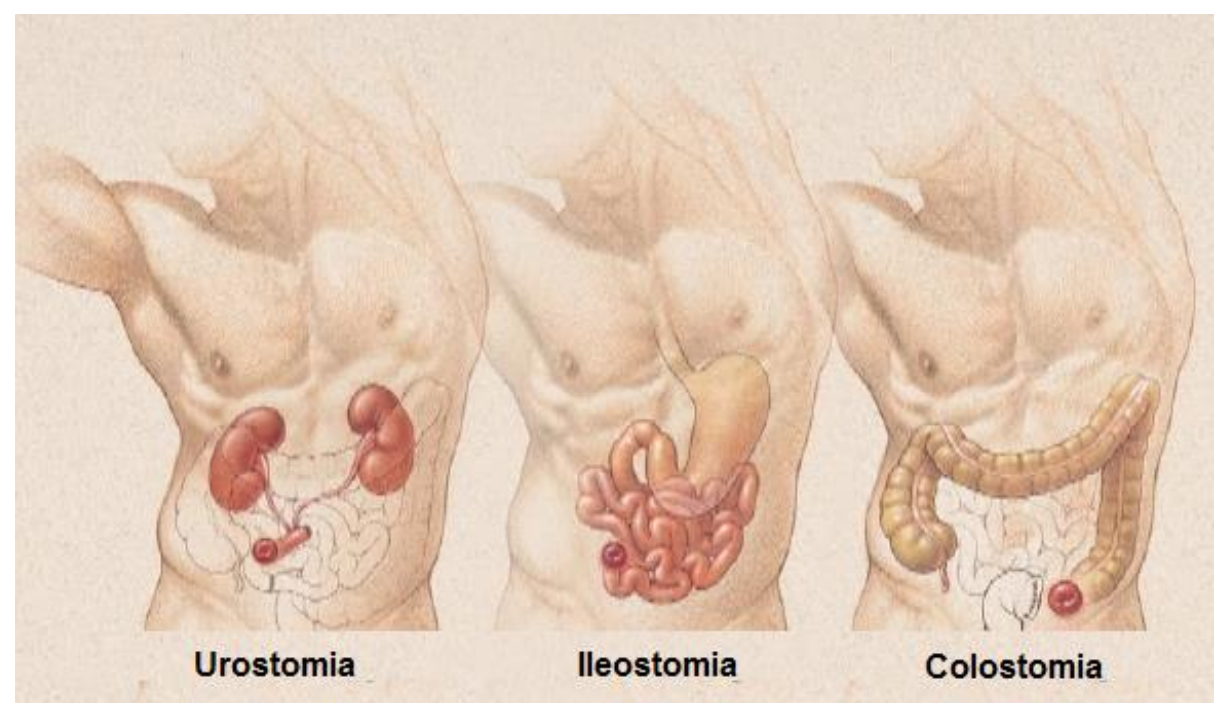

Figura 1 - Tipos de estomias.

Fonte: http://expressmedical.blogspot.com.br/

As estomias podem ser classificadas de acordo com sua função, como por exemplo para infusão de medicamentos, alimentação, descompressão ou evacuação; conforme o modo de confecção (fístula mucosa, em alça, terminal ou em uma ou dupla boca); de acordo com a continência (continente ou incontinente); altas ou baixas, segundo a posição em relação ao ângulo de Treitz (nas estomias digestivas) ou em relação ao ureter nas estomias urinárias (MURAGAKI; RAICHER, 2014).

Podem ainda ser classificadas de acordo com o local em que foram confeccionadas ou conforme o tempo de permanência, sendo temporárias ou definitivas. As estomias temporárias podem ser revertidas após um período de tempo e tem como objetivo a proteção de uma anastomose, descompressão ou restauração da função do órgão afetado. As estomias 
permanentes são realizadas quando há impossibilidade de reversão, geralmente em casos de câncer (MELO, 2010; SECCANI et al, 2007).

\subsubsection{Estomias do trato respiratório}

A Traqueostomia é considerada um dos procedimentos cirúrgicos mais antigos descritos na literatura. A primeira foi realizada no século II antes de Cristo e em 1977 foi realizada uma traqueostomia para retirada de corpo estranho de uma criança de 7 anos, sendo esta considerada a primeira traqueostomia confeccionada com sucesso nesta clientela (FRAGA; SOUZA; KRUEL, 2009; ITAMOTO et al, 2010).

Comumente realizado, o procedimento consiste na abertura da parede anterior da traqueia para o meio externo (linha média do pescoço, abaixo da cartilagem cricoide), diminuindo a resistência respiratória, possibilitando a ventilação pulmonar e facilitando a remoção de secreções traqueobrônquicas presentes em excesso, além de evitar traumas causados pela intubação prolongada (PRIANTE; CARDOSO, 2014; KAYO et al, 2015).

A técnica utilizada para confecção da traqueostomia pode ser a cirúrgica aberta clássica ou a percutânea. Na cirurgia aberta, o paciente é posicionado adequadamente e sedado no centro cirúrgico. Após marcação dos pontos anatômicos que servirão de referência, é feita uma incisão horizontal para exposição dos anéis traqueais e, em seguida, abre-se a parede anterior da traqueia. Nas crianças, assim como nos adultos, é importante a colocação de pontos de reparo na parede da traqueia, pois estes servirão de referência para canulação nos casos em que ocorrer a decanulação (FRAGA; SOUZA; KRUEL, 2009; SILVA, 2014).

$\mathrm{Na}$ técnica de traqueostomia percutânea, realiza-se uma incisão abaixo da cartilagem cricoide, preferencialmente entre o $2^{\circ}$ e o $3^{\circ}$ anéis traqueais, e a passagem de um fio-guia que conduzirá os dilatadores para a luz da traqueia. Existem kits no mercado que são utilizados para realização desta técnica, que geralmente é feita à beira do leito do paciente (TEDDE et al, 2015; SILVA, 2014).

Ao escolher a cânula de traqueostomia alguns fatores devem ser considerados, como resistência das vias aéreas superiores do paciente e as dimensões da traqueia, material que foi confeccionada (de preferência que seja de material que cause pouca ou nenhuma reação de hipersensibilidade) e com consistência suficiente para se moldar ao pescoço e traqueia sem causar pressão, lesão na pele e/ou desconforto, comprimento e diâmetro adequados, com ou sem balonete insuflável, com conector para encaixe do equipamento de ventilação mecânica, 
com tubo interno removível para possibilitar a higiene, entre outros (SILVA, 2014; FRAGA; SOUZA; KRUEL, 2009).

Em relação à troca da cânula de traqueostomia, embora não haja consenso em relação à frequência em que este procedimento deva ser realizado e, não sendo procedimento privativo de nenhum profissional, o Conselho Regional de Enfermagem de Santa Catarina, assim como o de outros estados, emitiu parecer concluindo que o enfermeiro é um profissional que, assegurada a capacidade técnica, tem competência técnico-científica para realizar a troca da cânula externa e interna, recomendando que se atue em conjunto com outros profissionais de saúde e que este procedimento esteja descrito em protocolo institucional (COREN-SC, 2015).

A confecção da traqueostomia pode ter finalidade preventiva, quando complementam procedimentos que podem gerar obstrução de vias aéreas e/ou dificuldade respiratória; curativa, quando assegura a manutenção das vias aéreas em casos de obstrução por neoplasias, estenose, edema de glote, entre outros; e paliativa, quando confeccionada para promover conforto respiratório em pacientes sem possibilidade de tratamento (RICZ et al, 2011; HORTENSE, 2014).

$\mathrm{Na}$ população pediátrica, a traqueostomia está indicada nos casos de intubação orotraqueal prolongada, doença neuromuscular, estenose subglótica, traqueomalácia, malformações graves no trato respiratório alto, neoplasias na cavidade oral e na cervical (ITAMOTO et al, 2009; KAYO et al, 2015). O Quadro 1 mostra as principais indicações de traqueostomia nas crianças.

Quadro 1 - Indicação de traqueostomia na população pediátrica.

\begin{tabular}{|l|c|l|}
\hline & Obstrução na via aérea superior & $\begin{array}{l}\text { Higiene pulmonar, ventilação } \\
\text { assistida }\end{array}$ \\
\hline Alérgicas & Angioedema, anafilaxia & Asma \\
\hline Metabólicas & - & $\begin{array}{l}\text { Fibrose cística; coma devido a } \\
\text { diabetes; uremia, etc.; síndrome } \\
\text { da angústia respiratória }\end{array}$ \\
\hline Profilática & $\begin{array}{l}\text { Cirurgia de cabeça e pescoço; } \\
\text { neurocirurgia; cirurgia cardíaca; } \\
\text { intubação prolongada }\end{array}$ & \\
\hline
\end{tabular}




\begin{tabular}{|c|c|c|}
\hline $\begin{array}{l}\text { Degenerativas/ } \\
\text { idiopáticas }\end{array}$ & Paralisia das cordas vocais & 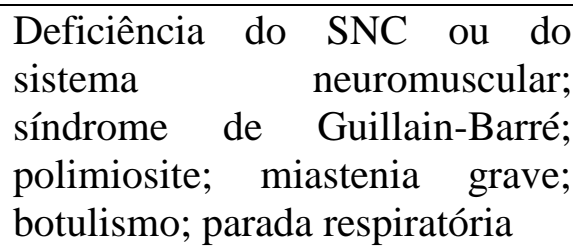 \\
\hline Desordens do sono & $\begin{array}{l}\text { Colapso da musculatura faríngea; } \\
\text { hipertrofia da adenoide/amígdala }\end{array}$ & - \\
\hline Congênitas & $\begin{array}{l}\text { Atresia de coanas; macroglossia; } \\
\text { sequência de Pierre-Robin; } \\
\text { laringomalacia; estenose de } \\
\text { laringe; paralisia das cordas } \\
\text { vocais; estenose subglótica; } \\
\text { hipoplasia traqueal, entre outros }\end{array}$ & $\begin{array}{lr}\text { Doença cardíaca e insuficiência } \\
\text { cardíaca congênitas; } \\
\text { esôfresia de } \\
\text { traqueoesofágica; com } & \text { fístula } \\
\text { pulmonar poplasia } \\
\text { diafragmática }\end{array}$ \\
\hline Trauma & $\begin{array}{l}\text { Injúria oral e facial; corpo } \\
\text { estranho; queimaduras; edema } \\
\text { laríngeo; fratura laríngea; lesão do } \\
\text { nervo laríngeo recorrente. }\end{array}$ & $\begin{array}{l}\text { Trauma craniano; pneumotórax; } \\
\text { após transplante de pulmão; } \\
\text { hemorragia intrapulmonar; } \\
\text { esmagamento torácico }\end{array}$ \\
\hline Tóxico & Corrosivos & $\begin{array}{l}\text { Síndromes aspirativas } \\
\text { e outras); coma tónio } \\
\text { (fenobarbital e outros) }\end{array}$ \\
\hline Infecção & $\begin{array}{lr}\text { Difteria; tétano; } & \begin{array}{r}\text { raiva; } \\
\text { laringotraqueíte; } \\
\text { epiglotite; }\end{array} \\
\text { gengivoestomatite; } & \text { abscesso } \\
\text { retrofaríngeo } & \end{array}$ & $\begin{array}{l}\text { Meningite; abscesso cerebral; } \\
\text { poliomielite; aspiração pulmonar } \\
\text { com indicação de fechamento } \\
\text { laríngeo; encefalite; pneumonia; }\end{array}$ \\
\hline Neoplasias & $\begin{array}{l}\text { Tumores de língua, laringe, } \\
\text { faringe e traqueia (sarcoma, } \\
\text { hemangioma, linfangioma e } \\
\text { papiloma); }\end{array}$ & $\begin{array}{l}\text { Tumor cerebral e em medula } \\
\text { espinhal }\end{array}$ \\
\hline
\end{tabular}

Fonte: FRAGA; SOUZA; KRUEL, 2009.

Para crianças submetidas ao procedimento de confecção da traqueostomia, alguns cuidados são fundamentais como realizar a aspiração cuidadosa e frequente para manter a permeabilidade da cânula endotraqueal, umidificar o ar ambiente, higienizar a região ao redor da estomia, fixação adequada da cânula para evitar seu deslocamento e, consequentemente, lesões na traqueia que levem à formação de tecido de granulação e estenose (KAYO et al, 2015; TEDDE et al, 2015). 


\subsubsection{Estomias do sistema digestório}

\section{Esofagostomia}

A esofagostomia é confeccionada realizando-se uma abertura no esôfago cervical, localizado entre a traqueia e a coluna cervical, sendo melhor abordado pela lateral esquerda do pescoço. Em crianças, é normalmente indicada nos casos de atresia do esôfago sem fístula, cuja função é impedir a aspiração de saliva (ROCHA; VELHOTE, 2015).

Por causa da dificuldade de adaptação de equipamento coletor no pescoço da criança para conter os efluentes da esofagostomia, a região periestoma torna-se frequentemente úmida, favorecendo a ocorrência de infecções fúngicas. Além da avaliação frequente da pele periestoma, a fim de evitar o surgimento de complicações, é importante que se estimule a sucção/mastigação e a coordenação da deglutição para evitar a recusa dos alimentos após a cirurgia de reconstrução do trânsito alimentar (CARVALHO, 2003; ROCHA; VELHOTE, 2015).

\section{Gastrostomia}

A gastrostomia é um procedimento comumente realizado, tanto na fase adulta quanto na infância. A primeira gastrostomia foi relatada em 1786 por August Stanislas Verneuil e novas tecnologias para administração das dietas enterais foram desenvolvidas a partir da década de 1980, melhorando as técnicas de inserção do cateter e os materiais utilizados na confecção do mesmo (BERTEVELLO; SOBREIRA; MORAIS, 2015).

Geralmente a gastrostomia é confeccionada para descompressão gastrointestinal, por exemplo, no caso dos pacientes com obstrução por tumor abdominal não ressecável; para alimentação, em pacientes com disfagia mecânica (malformações, estenose, etc.) ou funcional, nos casos de distúrbios motores da faringe ou esôfago, risco elevado de broncoaspiração, entre outros (PRIANTE; CARDOSO, 2014). Em crianças, a gastrostomia tem como indicação principal a alimentação a médio e longo prazo, em casos de doenças neurológicas, incapacidade de deglutição, atresia de esôfago e estenose cáustica ou péptica do esôfago (ROCHA; VELHOTE, 2015).

O procedimento de confecção da gastrostomia consiste na abertura de um orifício na parede do abdome, comunicando o estômago com o meio externo, podendo ser realizado por laparotomia, endoscopia, laparoscopia ou videolaparoscopia (SANTOS et al, 2011; BERTEVELLO; SOBREIRA; MORAIS, 2015). As técnicas mais utilizadas para confecção 
da gastrostomia são a de Stamm e de Witzel, devido a segurança da execução de ambas, porém a gastrostomia endoscópica percutânea também é um método bastante utilizado pela eficácia e segurança, inclusive quando realizado em recém-nascidos (ROCHA; VELHOTE, 2015).

Na gastrostomia tipo Stamm, a câmara gástrica é acessada através de pequena incisão supraumbilical; no estômago, o local mais adequado para fixação do cateter é na transição corpo-antro, próximo à grande curvatura e, logo após a passagem do cateter, realiza-se a fixação do estômago na parede abdominal, para evitar o extravasamento de conteúdo gástrico para a cavidade peritoneal do abdome. Na gastrostomia tipo Witzel, o orifício é confeccionado na camada serosa do estômago, objetivando a criação de um túnel para evitar o extravasamento de conteúdo intragástrico (de maneira mais eficaz que a técnica de Stamm); o cateter é fixado ao longo da parede anterior do estômago apenas com uma sutura em bolsa, e sobre ele são realizados pregueamentos (na parede gástrica). A técnica de Stamm normalmente é escolhida, quando comparada à de Witzel, pela facilidade de realização da mesma (BERTEVELLO; SOBREIRA; MORAIS, 2015; SANTOS et al, 2011; LALANDE, 2011).

A Gastrostomia Endoscópica Percutânea (PEG), desenvolvido a partir de 1980, tem sido o método de escolha em diversos serviços de saúde no Brasil e em outros países quando há necessidade de nutrição enteral prolongada, devido ao baixo custo e relativa facilidade técnica, já que exige menos tempo na execução do procedimento, não há necessidade de anestesia geral e o paciente permanece internado por um período de tempo menor (BERTEVELLO; SOBREIRA; MORAIS, 2015; NASCIMENTO; BORGES; DONOSO, 2015; SANTOS et al, 2011). O procedimento é iniciado por uma esofagogastroduodenoscopia e, na ausência de condições anormais do esôfago ou estômago que contraindiquem a realização da gastrostomia, a PEG é realizada. Incialmente o estômago é inflado com ar; uma agulha é introduzida por uma pequena incisão na parede abdominal anterior, pela qual se passa um fio-guia que é retirado pela boca do paciente. Em seguida, amarra-se o cateter ao fio-guia e este é levado ao estômago, exteriorizando-o pela incisão; uma tração é mantida para garantir a aderência do estômago à parede do abdome (BERTEVELLO; SOBREIRA; MORAIS, 2015; ROCHA; VELHOTE, 2015).

Por ser um procedimento menos invasivo, a confecção por endoscopia é a técnica escolhida quando não há necessidade de cirurgia adicional; entretanto, tal procedimento é 
contraindicado nos casos de esplenomegalia ou hepatomegalia, ascite, obstrução no esôfago e coagulopatia, mesmo estando associado a um número menor de complicações (LALANDE, 2011; SCHRAG et al, 2007). O Quadro 2 exemplifica as contraindicações da confecção de gastrostomia por via endoscópica.

Quadro 2 - Contraindicações específicas da técnica de confecção da gastrostomia por via endoscópica.

\begin{tabular}{|l|}
\hline Transiluminação da parede gástrica impossibilitada por: \\
- Obesidade \\
- Cicatriz da parede abdominal \\
\hline Cirurgia abdominal prévia \\
\hline $\begin{array}{l}\text { Incapacidade de aproximação da parede gástrica à parede abdominal por: } \\
\text { - Hepatomegalia } \\
\text { - Esplenomegalia }\end{array}$ \\
\hline Estreitamento de orofaringe ou de esôfago \\
\hline Tumor \\
\hline
\end{tabular}

Fonte: BERTEVELLO; SOBREIRA; MORAIS, 2015.

Um cateter é mantido no orifício da gastrostomia, sendo os mais utilizados os de Pezzer, Foley, Malecot ou uretral, que podem ser siliconados, de látex ou de poliuretano, com comprimento de cerca de $35 \mathrm{~cm}$ e diâmetro variando entre 9 e 24 French (PRIANTE; CARDOSO, 2014; BERTEVELLO; SOBREIRA; MORAIS, 2015). Na população pediátrica, comumente utiliza-se o cateter de baixo perfil, que são confeccionados com silicone biocompatível e possuem válvula antirrefluxo, com tamanhos que variam de acordo com a espessura abdominal e dieta que será infundida. São mais resistentes e estéticos, além de possuírem maior durabilidade, podendo ser trocados, em média, a cada seis ou oito meses (KAYO et al, 2015; LALANDE, 2011).

Não há necessidade de troca rotineira do cateter e não existe intervalo de troca definido na literatura, deste modo, o enfermeiro deve estar atendo às características do cateter, como integridade (presença ou ausência de ruptura ou deterioração) e permeabilidade, além de avaliar com frequência a região periestoma, a fim de identificar precocemente possíveis complicações como obstrução, extravasamento de conteúdo gástrico, sangramentos, granuloma, entre outros. Nos casos em que exista a necessidade da troca do cateter de gastrostomia, o enfermeiro estomaterapeuta é o profissional capacitado para executar tal 
procedimento, podendo também ser realizado pelo enfermeiro generalista desde que este tenha segurança e treinamento para executá-lo (COFEN, 2013).

\section{Jejunostomia}

A jejunostomia possibilita uma via de acesso pós-pilórica (jejuno proximal) e a alça jejunal escolhida deve distar no mínimo $20 \mathrm{~cm}$ do ângulo duodenojejunal (ângulo de Treitz). Sua principal indicação é para a nutrição enteral em pacientes com condições nutricionais precárias, mas que tenham o trato intestinal sem alterações, sendo contraindicada nos casos de obstrução intestinal, fístula ou perfuração (PAULA; SPERANZINI, 2014).

A confecção da jejunostomia normalmente é realizada por laparotomia, laparoscopia ou endoscopia. Quando se opta pela laparotomia, a técnica de Witzel é a mais utilizada; quando endoscopia é a opção, duas técnicas podem ser utilizadas: gastrojejunostomia endoscópica percutânea ou jejunostomia endoscópica percutânea (SANTOS et al, 2011; PAULA; SPERANZINI, 2014).

A gastrojejunostomia endoscópica percutânea está indicada nos casos em que o indivíduo apresente risco elevado para aspiração de conteúdo gástrico ou não tolerem alimentação via gastrostomia. Neste procedimento, uma extensão para o jejuno é instalada a partir de uma gastrostomia endoscópica, com auxílio de um fio-guia. O cateter de escolha habitualmente tem entre 8,5 a 12 Fr. Na jejunostomia endoscópica percutânea, o procedimento é semelhante ao da gastrostomia endoscópica percutânea; a punção percutânea abdominal é orientada por transiluminação e, com o auxílio de um trocarte, se introduz um fio-guia que é tracionado até a boca do paciente. Em seguida, é fixado o cateter no fio-guia e este será conduzido até o jejuno. É indicada nos casos de intolerância alimentar pela gastrostomia, nos casos de gastrectomia total ou quando se necessita de suporte nutricional definitivo (SANTOS et al, 2011).

Um cateter nasoentérico é comumente utilizado no orifício da jejunostomia pela facilidade de introdução e monitorização de sua localização. Entretanto, o uso deste cateter tem suas complicações, como risco de deslocamento acidental, risco de aspiração e obstrução do cateter, devido ao seu pequeno calibre (PAULA; SPERANZINI, 2014). Uma complicação grave que pode ocorrer na população pediátrica com jejunostomia é a septicemia associada à enterite grave, decorrente da infusão de dietas não estéreis. Deste modo, é de fundamental importância que a dieta seja estéril e administrada em temperatura ambiente, com fluxo 
contínuo para evitar náuseas e cólicas abdominais, entre outros sintomas (CARVALHO, 2003).

A troca do cateter de jejunostomia deve ser realizada preferencialmente pelo enfermeiro estomaterapeuta e, na ausência deste, pelo enfermeiro generalista desde que comprovada sua competência para executar tal procedimento (COFEN, 2013).

\section{Ileostomia}

A primeira ileostomia foi confeccionada em 1879 por um cirurgião alemão (Baum), em caráter provisório, em um paciente com câncer no cólon ascendente. Entretanto, desde o início da realização deste procedimento, altos índices de morbidade e mortalidade eram observados. A partir de 1930, quando a ileostomia foi confeccionada em local diferente da incisão cirúrgica principal por McBurney, surgiram novas ideias para a técnica cirúrgica em si (SANTOS; CESARETTI, 2015).

A ileostomia é confeccionada na parede do íleo e exteriorizada através da parede abdominal anterior (quadrante inferior direito) para desviar o efluente para o meio externo, com protrusão de cerca de $3 \mathrm{~cm}$ e aspecto mamilar, sendo necessária a utilização de equipamento coletor para contê-lo (PAULA; SPERANZINI, 2014; ROCHA, 2011; KAYO et al, 2015; POGGETO et al, 2012). A ileostomia se torna funcionante em dois a três dias após a realização da cirurgia e seu efluente apresenta coloração amarelo-esverdeada, $\mathrm{pH}$ alcalino e odor ácido ou ausente. O volume do efluente da criança ileostomizada é de cerca de $1 \mathrm{~mL} / \mathrm{Kg} / \mathrm{h}$ e elas estão suscetíveis ao desequilíbrio hidroeletrolítico, sendo necessária a observação frequente de sinais e sintomas de desidratação (letargia, fontanela deprimida, volume urinário diminuído, etc.), além do controle da ingesta hídrica (KAYO et al, 2015).

As ileostomias mais comuns são a terminal ou ileostomia a Brooke e a ileostomia em alça. A ileostomia terminal (ou ileostomia a Brooke) é indicada para tratamento de doenças como retocolite ulcerativa, polipose adenomatosa familiar, doença de Crohn, entre outras que exigem a retirada parcial do íleo e não há como restabelecer o trânsito intestinal. A ileostomia em alça é indicada nos casos de obstrução do cólon, proteção de anastomoses colônicas de risco, no caso de cirurgias realizadas no reto, sepse perianal extensa, como nos casos de Síndrome de Fournier, e na presença de fístula retovaginal (PAULA; SPERANZINI, 2014; HABR-GAMA; NETO; ARAÚJO, 2015). 
A ileostomia em alça com bolsa ileal em $\mathbf{J}$ é confeccionada nos casos de proctocolectomia total, quando tem-se a ressecção de todo o segmento colorretal e realiza-se a anastomose do íleo com o canal anal. A bolsa em J serve de reservatório, permitindo que o paciente tenha melhor controle da urgência evacuatória. A ileostomia de proteção em alça é confeccionada, mesmo na presença da bolsa ileal em J, para desviar o efluente para a estomia e evitar a reabordagem cirúrgica devido a peritonite, fístula ou abscesso, sendo fechada a partir de 8 semanas (HABR-GAMA; NETO; ARAÚJO, 2015).

Algumas complicações relacionadas às ileostomias podem surgir, como déficit de nutrientes (vitamina B12, magnésio, potássio), diarreia, prolapso, edema, separação cutaneomucosa, dermatite, entre outros. É de suma importância a orientação em relação à dieta dos pacientes ileostomizados, com a introdução de fibras gradativamente na dieta (evitando-se a ingesta nas primeiras seis semanas após a cirurgia) e promoção da ingesta hídrica, assim como a identificação de sinais e sintomas que indiquem obstrução intestinal, como náuseas, vômitos e distensão abdominal (KAYO et al, 2015; CARVALHO, 2003).

\section{Colostomia}

Não há consenso na literatura em relação à confecção da primeira colostomia. Contudo, Alex Littré é considerado o pai da colostomia por ter realizado em 1710 uma autopsia em um recém-nascido que faleceu por malformação retal, constatando durante a autopsia que poderia ter exteriorizado a alça intestinal na parede do abdome e, com isso, resolvido o problema da criança. Assim sendo, Littré é considerado o idealizador do procedimento de confecção da colostomia sem tê-lo realizado (SANTOS; CESARETTI, 2015).

A colostomia é confeccionada a partir de uma abertura realizada na parede do intestino grosso, com exteriorização da alça intestinal no abdome anterior para desviar o efluente para o meio exterior. Normalmente é confeccionada para tratamento de pacientes com obstrução intestinal devido a neoplasias, doença diverticular complicada, processos inflamatórios e hemorrágicos agudos, entre outros (PAULA; SPERANZINI, 2014). Nas crianças, a colostomia é o tipo de estomia intestinal comumente realizada para manejo de doenças congênitas ou adquiridas, como a doença de Hirschsprung, malformações anorretais (por exemplo, ânus imperfurado), enterocolite necrotizante, atresia intestinal e íleo meconial (KAYO et al, 2015). 
O local em que será confeccionada a estomia depende da patologia, da urgência do procedimento e das condições clínicas do paciente, sendo feita geralmente onde há mobilidade do cólon, como ceco, cólon transverso ou sigmoide. As colostomias podem ser classificadas de acordo com o modo e o local em que foram confeccionadas, como a colostomia em alça, colostomia terminal, colostomia úmida e a colostomia perineal (PAULA; SPERANZINI, 2014).

A colostomia em alça é comumente realizada em caráter temporário, podendo ser confeccionada no cólon transverso (quadrante superior direito ou esquerdo do abdome) ou sigmoide. Escolhido o segmento que será exteriorizado, uma laparotomia ou uma incisão direta no quadrante onde ficará localizada são as técnicas de escolha para confecção da estomia. Um cateter de polietileno é utilizado para sustentação da alça exteriorizada e para evitar a retração da mesma, sendo removido em torno de dez dias (PAULA; SPERANZINI, 2014).

A colostomia terminal é confeccionada no quadrante inferior esquerdo do abdome, devendo a alça ser exteriorizada sem tensão excessiva e com suprimento sanguíneo adequado, com abertura que permita a passagem de dois dedos a fim de não "angustiar" o segmento e permitir que o procedimento de irrigação da colostomia seja realizado futuramente pelo paciente colostomizado. A protrusão da colostomia terminal varia de 1 a 1,5 cm (PAULA; SPERANZINI, 2014).

A colostomia úmida foi descrita a primeira vez em 1989 por Carter e Garnet e está indicada nos casos em que é necessário o desvio concomitante das vias fecal e urinária, sendo então confeccionada uma estomia em alça com dupla boca para esta finalidade, permitindo a drenagem de urina, na porção distal, sem contato com o efluente intestinal que é drenado na porção proximal. Uma válvula antirrefluxo é realizada na anastomose dos ureteres com o conduto urinário para evitar o refluxo de urina; um bastão de sustentação é mantido para evitar a retração da estomia e um cateter do tipo pig tail é introduzido na porção distal (derivação urinária), sendo mantido por quinze dias (PAULA; SPERANZINI, 2014; BANDEIRA; GUIMARÃES, 2015).

Em 1991, o cirurgião brasileiro Alcino Lázaro da Silva desenvolveu a técnica de amputação abdominoperineal do reto (APR) com colostomia perineal. A técnica consiste na realização de três miotomias na camada seromuscular do cólon sigmoide após a APR, distantes de 8 a $10 \mathrm{~cm}$ entre si, sendo separadas posteriormente para criação das válvulas 
colônicas. A porção distal do cólon intestinal é fixada no períneo, realizando-se a colostomia perineal, evitando assim a confecção da estomia na parede do abdome e o uso de equipamento coletor para conter as fezes (OLIVEIRA; MELANI, 2015; PAULA; SPERANZINI, 2014; ROCHA, 2011).

A irrigação da colostomia é um método que também pode ser utilizado para regular a atividade intestinal em pacientes com colostomia perineal, mas com adaptações; a técnica consiste na introdução de água em temperatura ambiente (entre 500 e $1.500 \mathrm{~mL}$ ) no orifício da estomia, permitindo o controle da eliminação fecal por um período regular. Todavia, os pacientes com colostomia perineal devem ter acompanhamento criterioso durante seu processo de reabilitação, para evitar que o volume de água infundido comprometa as suturas das válvulas colônicas, entre outras complicações (OLIVEIRA; MELANI, 2015).

As características das fezes variam de acordo com a localização anatômica em que foi confeccionada a colostomia. Os efluentes da colostomia em alça ascendente, exteriorizada no quadrante inferior direito, têm consistência que varia de líquida à pastosa; na colostomia em alça transversa, exteriorizada no quadrante inferior ou superior direito ou esquerdo do abdome, as fezes têm uma consistência que variam de pastosa à semiformada; na colostomia descendente, exteriorizada no quadrante inferior esquerdo, as fezes têm uma consistência variando de semiformada a formada (KAYO et al, 2015).

No pós-operatório imediato de cirurgias que têm como objetivo a confecção de estomias intestinais e que seja necessária a utilização de equipamento coletor, é importante que este seja de material transparente e drenável, de uma peça, para que possibilite a observação das características da estomia e de seu efluente. É importante considerar também as características da pele da criança, de acordo com sua idade, assim como o tamanho pequeno das estomias, proximidade da incisão cirúrgica com o coto umbilical, estomias múltiplas, complicações existentes, disponibilidade de equipamentos coletores e adjuvantes, entre outras (KAYO et al, 2015), para que o cuidado seja prestado de maneira individualizada segundo as necessidades e particularidades de cada criança.

\subsubsection{Estomias do trato urinário}

Os estomas urinários mantêm a drenagem da urina produzida pelos rins para o meio externo para que não haja retorno para o trato urinário superior ou que este retorno seja mínimo. Estão indicados nos casos de tumores no trato urinário, anomalias anatômicas 
congênitas ou adquiridas e lesões funcionais graves, podendo ser classificadas conforme sua continência e localização, sendo continentes ou incontinentes, ortotópicas (quando se abrem na uretra) ou heterotópicas (quando a urina escoa por meio de estomias cutâneas e não através da uretra) (MACIEL, 2014).

Nas estomias urinárias continentes é importante que o estoma não tenha protrusão, ou seja, que não ultrapasse o nível da pele e a mucosa não seja exposta, evitando assim a produção de serosidade; neste tipo de estomia, pode ser necessário a realização de cateterismo intermitente no início ou definitivamente. Nas estomias urinárias incontinentes, tem-se a inversão de 2 a $3 \mathrm{~cm}$ distais da alça eferente, o que torna possível a utilização de equipamentos coletores já que estes estomas tem uma protrusão (RODRIGUES, 2015). As estomias urinárias mais conhecidas são: cistostomia, vesicostomia, ureterostomia, nefrostomia e pielostomia.

\section{Vesicostomia}

Em 1913 a necessidade de drenagem vesical era tida como indispensável para o alívio pressórico vesical após neurocirurgias, pois os pacientes submetidos a este procedimento quase sempre desenvolviam quadros de retenção urinária. $\mathrm{O}$ conceito de alívio pressórico relacionado ao trato urinário popularizou as vesicostomias, como forma de preservar a função renal, estendendo-se a diversas situações clínicas como nos casos de bexiga neurogênica congênita e em traumas medulares (RODRIGUES, 2015).

A vesicostomia é a exteriorização da parede da bexiga junto à pele do abdome, com objetivo de descompressão do órgão. O orifício da estomia se entreabre permitindo a drenagem de urina à medida que a bexiga se enche. Atualmente tem se introduzido um cateter na vesicostomia para controlar melhor a drenagem de urina e como forma de treinamento para a recuperação da função vesical (ROCHA; VELHOTE, 2015; MURAGAKI; RAICHER, 2014).

A bexiga pode ser ampliada para aumentar sua capacidade de armazenamento de urina utilizando-se segmentos do intestino delgado ou grosso, criando-se assim um local de baixa pressão, embora haja riscos de complicações a curto ou longo prazo dependendo do segmento de escolha, como por exemplo a estenose (STEIN; SCHRÖDER; THÜROFF, 2012).

Normalmente a vesicostomia é confeccionada em crianças com obstrução infravesical e que necessitam de proteção dos rins e/ou ureteres até que seja realizado o tratamento 
definitivo da obstrução (MACIEL, 2014). A vesicostomia cutânea (incontinente) é recomendada nos casos em que o paciente seja incapaz de realizar o cateterismo intermitente limpo por apresentar limitações físicas ou mentais (STEIN; SCHRÖDER; THÜROFF, 2012).

\section{Nefrostomia}

A nefrostomia é uma derivação externa do trato urinário superior que pode ser feita por técnica aberta ou por punção guiada por ultrassonografia; um cateter de Petzer, Malecot ou Foley é inserido através do parênquima renal com a finalidade de descompressão temporária ou definitiva nos casos de obstrução parcial ou total da pelve renal (MURAGAKI; RAICHER, 2014; ROCHA; VELHOTE, 2015).

A nefrostomia percutânea consiste em um procedimento onde uma punção diretamente no rim obstruído é guiada por fluoroscopia, em seguida a via é dilatada para introdução de um cateter com auxílio ou não de um fio-guia. Esta técnica foi descrita em 1955 por Goodwin e colaboradores, sendo revista alguns anos depois. Pederson realizou a primeira nefrostomia percutânea guiada por ultrassonografia e, nas últimas duas décadas, relatou-se uma taxa de sucesso de $92 \%$ na realização deste procedimento (KARIM et al, 2010).

Apesar das altas taxas de sucesso, este procedimento pode estar associado a complicações como punção de órgãos adjacentes, pneumotórax, fístula arteriovenosa renal, sangramento no local da punção com presença ou não de hematúria, infecções, entre outros (DYER et al, 2002). Deste modo, os enfermeiros devem realizar um plano de cuidados individualizado para os pacientes com nefrostomia, observando as características do sítio de inserção do cateter, características da urina drenada, realizar balanço hídrico rigoroso, controle dos sinais vitais, realizar curativo e irrigação do cateter de nefrostomia, etc., ficando a troca do cateter sob responsabilidade dos profissionais da medicina (COREN-PR, 2013).

\section{Pielostomia}

$\mathrm{Na}$ pielostomia há a exteriorização da pelve renal junto à pele, entretanto este procedimento não é realizado rotineiramente. Possui as mesmas indicações da nefrostomia, porém traz benefícios como ausência do cateter no rim evitando a presença de corpo estranho e não torna o ureter e a bexiga completamente disfuncionais (MURAGAKI; RAICHER, 2014).

Devido à ausência de cateter na pelve renal, faz-se necessário a utilização de equipamentos coletores para conter o fluxo contínuo de urina, evitando o contato desta com a 
pele periestoma. As complicações mais frequentes relacionadas a este tipo de estomia são estenose, retração e dermatite amoniacal (MURAGAKI; RAICHER, 2014).

\section{Ureterostomia}

Na ureterostomia ocorre a exteriorização do ureter na pele, podendo ser temporária ou definitiva. Apresenta as mesmas indicações da pielostomia e da nefrostomia, porém com a facilidade de reversão cirúrgica e preservação das funções urinárias quando confeccionada em alça, dupla boca ou com exteriorização proximal com anastomose distal (MURAGAKI; RAICHER, 2014). É um tipo de estomia que não é confeccionada habitualmente, devido a ocorrência de complicações frequentes como a estenose, retração, infecção urinária, entre outros (MACIEL, 2014; MURAGAKI; RAICHER, 2014).

As ureterostomias proximais são confeccionadas nos casos de obstrução na junção ureterovesical ou em casos graves de insuficiência renal e pós-renal. As ureterostomias baixas são confeccionadas nos casos de litíase ureteral, traumas nos ureteres, obstrução mecânica vesical e obstrução ureterovesical (MURAGAKI; RAICHER, 2014).

Os pais de crianças com estomias urinárias incontinentes devem ser orientados pelo enfermeiro especialista em estomaterapia ou o profissional treinado para observar as características da urina da criança, bem como ingesta hídrica (sendo $35 \mathrm{~mL} / \mathrm{kg}$ de peso o recomendado), higiene e proteção da pele periestoma a fim de evitar possíveis complicações (KAYO et al, 2015).

\section{Cistostomia}

Em 1561, o cirurgião Pierre Franco foi o primeiro a abordar a bexiga por via suprapúbica e, no final do século XIX, novos procedimentos foram descritos, permitindo o acesso à bexiga por via suprapúbica extraperitoneal, tornando este procedimento amplamente utilizado (COLOGNA, 2011).

A cistostomia consiste em uma abertura da bexiga próxima à sua cúpula, sendo necessária a utilização de um cateter (Foley ou Owen) para drenagem da urina. É comumente utilizada no pós-operatório de cirurgias vesicais, pois proporciona melhor remoção do sangue da bexiga, ou no caso de lesões na uretra, períneo ou bacia (MURAGAKI; RAICHER, 2014).

A confecção da cistostomia se dá de duas maneiras: a céu aberto, quando há necessidade de expor a parede anterior da bexiga, nos casos de obstrução vesical, traumas na 
bexiga e/ou uretra, estenose de uretra, entre outros; por punção suprapúbica, realizando-se uma incisão na linha mediana e $4 \mathrm{~cm}$ acima da sínfise púbica após aplicação de anestésico local para introdução do trocar (em seguida o cateter é introduzido e fixado na pele do paciente). A indicação da cistostomia por punção suprapúbica é a mesma da confecção a céu aberto, entretanto, não é recomendada para pacientes que realizaram cirurgias pélvicas ou em radioterapia, pelo risco de lesão da alça intestinal ou do peritônio parietal (COLOGNA, 2011).

As principais desvantagens da cistostomia são a disfuncionalização da bexiga, a utilização do cateter para manter a drenagem da urina e a promoção de um menor grau de descompressão do trato urinário (MURAGAKI; RAICHER, 2014).

Nas crianças, comumente são utilizados cateteres de fino calibre, como os de 4 e 6 French (KAYO et al, 2015). A troca do cateter de cistostomia deve ser feita pelo enfermeiro estomaterapeuta quando necessária e, na falta deste profissional, pelo enfermeiro capacitado desde que comprovada sua competência, respeitando a técnica asséptica (SOBEST, 2008; COREN-SP, 2012; SMELTZER et al, 2012).

\subsection{Procedimento de demarcação das estomias}

A demarcação do local onde será confeccionada a estomia é um direito do paciente e facilita a realização de atividades de cuidado como a higiene da estomia e região periestoma, aderência do equipamento coletor, além de reduzir problemas como vazamento de efluentes, preocupações com a vestimenta e as complicações pós-operatórias (CESARETTI et al, 2015; PERSON et al, 2012). Este procedimento deve ser realizado pelo cirurgião coloproctologista e/ou pelo enfermeiro especialista em Estomaterapia (CESARETTI et al, 2015).

Cabe ressaltar que no Brasil o curso de especialização de Enfermagem em Estomaterapia segue os critérios estabelecidos pela World Council of Enterostomal Therapists (WCET) e pela Associação Brasileira de Estomaterapia (SOBEST), formando enfermeiros com conhecimento e habilidades para prestar cuidados aos pacientes com estomias, pacientes com feridas agudas e crônicas, incontinência urinária e anal, assim como pacientes com fístulas, drenos, tubos e cateteres (SANTOS; CESARETTI, 2015; SOBEST, 2008).

Segundo a Wound, Ostomy and Continence Nurses Society (WOCN) em colaboração com a American Society of Colon and Rectal Surgeons (ASCRS), alguns aspectos devem ser 
considerados no momento da avaliação do paciente para demarcação do local de confecção da estomia, como mobilidade do paciente, postura, rigidez muscular, dobras e/ou pregas abdominais, cicatrizes, características do abdome (protruso, globoso, flácido, etc.), presença de outras estomias, presença de hérnias, acuidade visual do paciente, destreza manual, mamas grandes e pêndulas, idade do paciente, diagnóstico, ocupação, tipo de estomia que será confeccionada, preferências do cirurgião e do paciente, entre outros (WOCN, 2014).

A avaliação do local onde será confeccionada a estomia é feita com o paciente em pé, sentado e deitado, considerando a distância entre o local selecionado e as características do abdome, tais como as dobras e/ou pregas cutâneas, turgor da pele, cicatriz umbilical, linhas naturais da cintura, prega inguinal, músculo reto do abdome, proeminências ósseas (costelas e crista ilíaca anterossuperior), assim como o local onde será realizada a incisão cirúrgica (WOCN, 2014; CESARETTI et al, 2015).

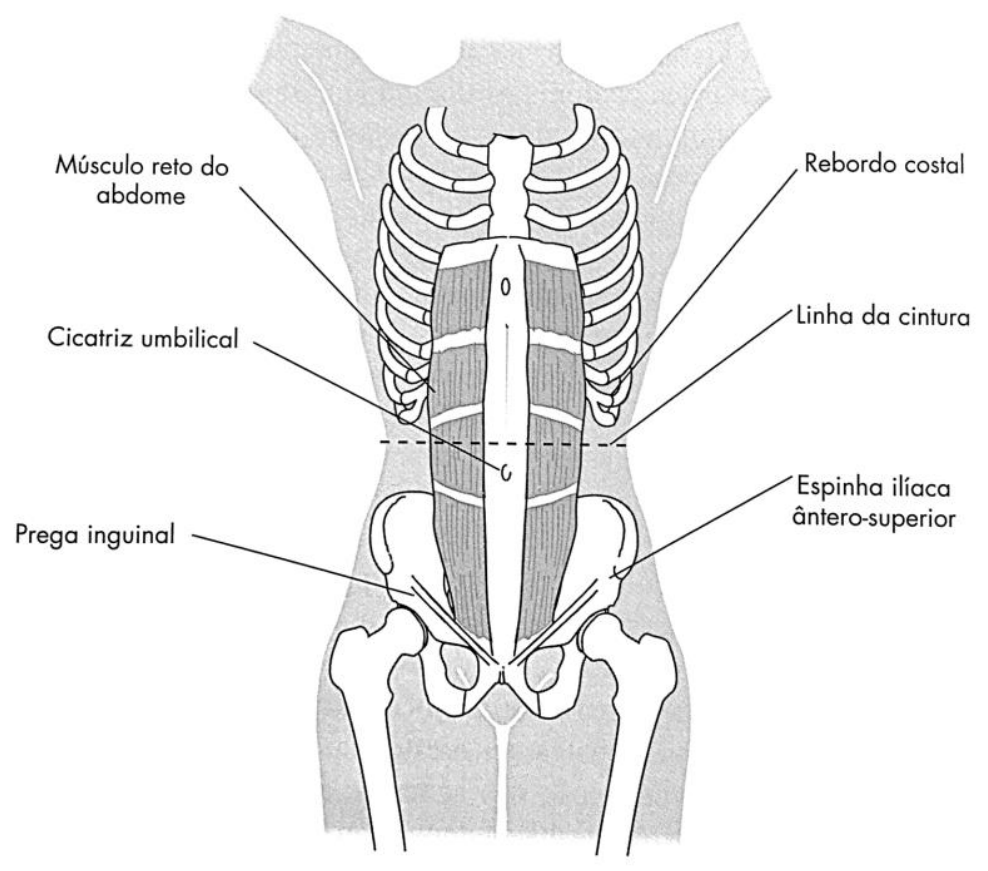

Figura 2 - Principais acidentes anatômicos a serem considerados na demarcação das estomias.

Fonte: CESARETTI et al, 2015.

Aconselha-se demarcar o local nos lados esquerdo e direito do abdome e identificar qual será o primeiro local de escolha, caso seja necessário alterar o local de confecção no momento cirúrgico. É de suma importância que o paciente consiga visualizar a estomia, e que esta fique localizada abaixo da linha de cintura para proporcionar maior comodidade e 
interferir o menos possível em seu estilo de vida, contribuindo também para as ações de autocuidado no pós-operatório (CESARETTI et al, 2015).

Apesar de não ser comum a realização da demarcação do local da estomia nas crianças, visto que a cirurgia para confecção é realizada em caráter de emergência na maioria dos casos, os critérios supracitados para seleção do local também podem ser utilizados para orientar a localização ideal para as estomias no abdome desta clientela. Recomenda-se evitar a região próxima ao rebordo costal e crista ilíaca, dando preferência para a confecção da estomia através do músculo reto do abdome, longe do coto umbilical ou umbigo, bem como evitar a confecção da estomia na parte inferior do abdome, pois os movimentos constantes das pernas podem interferir na aderência do equipamento coletor (CESARETTI et al, 2015; ROCHA; VELHOTE, 2015; KAYO et al, 2015; CESARETTI; PAULA, 2014).

\subsection{Complicações de estomias}

O aparecimento de complicações pós-operatórias relacionadas às estomias pode estar relacionado a múltiplos fatores, da mesma forma em que podem ocorrer na ferida cirúrgica. $\mathrm{O}$ planejamento de cuidados específicos no período pré-operatório, intraoperatório ou pósoperatório das cirurgias para confecção de estomias são importantes para evitar o surgimento dessas complicações, já que estas interferem significativamente no processo de reabilitação do paciente (PAULA; CESARETTI, 2014; SCHMIDT; HANATE, 2015).

Algumas complicações são imediatas, pois surgem nas primeiras 24 horas de pósoperatório (PO), como por exemplo a necrose da estomia, hemorragia e edema. Também podem ser classificadas como precoces, ocorrendo entre o primeiro e o sétimo dia de pósoperatório, como a separação cutaneomucosa, fístula e a retração da estomia. As complicações tardias se manifestam após a alta hospitalar ou até meses após a cirurgia, como por exemplo as hérnias paraestomais, prolapso de alça, retração da estomia, estenose, lesões pseudoverrucosas, dermatite periestoma, entre outras (PAULA; CESARETTI, 2014; PAULA, MATOS, 2015).

\section{Edema}

Comumente se observa a presença de edema na mucosa da estomia após a realização da cirurgia para confeccioná-la. Pode ser considerado uma resposta fisiológica do organismo ao trauma cirúrgico pela manipulação da alça intestinal, desaparecendo espontaneamente nas 
primeiras duas a seis semanas de pós-operatório. É importante que o enfermeiro acompanhe a evolução do edema, em conjunto com o paciente, pois esta condição pode levar à isquemia e necrose devido a diminuição do suprimento sanguíneo local (PAULA; CESARETTI, 2014; PAULA; MATOS, 2015; VIEIRA, 2014; BORGES; RIBEIRO, 2015).

\section{Isquemia e necrose}

Nas estomias intestinais, a isquemia pode ocorrer devido à tensão excessiva no mesentério ou arcada vascular, abertura estreita na parede abdominal onde será exposta a mucosa intestinal, hipovolemia sistêmica, entre outros, manifestando-se nas primeiras 24 horas após a cirurgia. A coloração da mucosa exteriorizada apresenta-se pálida no início, evoluindo para uma coloração violácea (PAULA; MATOS, 2015).

Na necrose, ocorre a morte do tecido da estomia como resultado da irrigação tecidual deficiente. Primeiro ocorre a isquemia do tecido, manifestando-se na mucosa da alça exteriorizada; em seguida, a mucosa adquire uma tonalidade que varia entre marrom e preto, sem o brilho característico da mucosa normal e com consistência macia e flácida. São fatores de risco para o surgimento da necrose: edema na parede do abdome, obesidade, suturas próximas ou apertadas, tensão excessiva no mesentério, embolia, hipotensão arterial, entre outros (PAULA; CESARETTI, 2014; WOCN, 2016).

A necrose, cuja incidência que varia de 2 a $10 \%$ nos pacientes com estomias intestinais, pode ser classificada em superficial, quando não compromete mais do que um terço da circunferência da estomia e o tecido necrótico se solta com a limpeza local, expondose o tecido róseo e saudável; profunda, quando o tecido necrótico atinge planos de aproximadamente $2 \mathrm{~cm}$ é necessária a ressecção do segmento afetado e, consequentemente, a reconstrução da estomia. (PAULA; CESARETTI, 2014; PAULA; MATOS, 2015; VIEIRA, 2014).

\section{Sangramento ou hemorragia}

O sangramento pode surgir com maior frequência no pós-operatório imediato, mas pode ocorrer também no pós-operatório mediato ou tardio. Geralmente o sangramento e/ou hemorragia estão associados à hemostasia inadequada dos vasos sanguíneos no momento cirúrgico, abertura na parede do abdome menor do que a base da estomia, trauma relacionado ao equipamento coletor, doença de base do paciente (diverticulite, polipose, neoplasias etc.), hipertensão portal, uso de antiagregantes plaquetários ou quimioterápicos, prática de esportes 
agressivos, entre outros, podendo ser necessária a revisão cirúrgica da estomia nos casos de sangramentos intensos (PAULA; CESARETTI, 2014; PAULA; MATOS, 2015; WOCN, 2016).

\section{Separação cutaneomucosa}

A separação cutaneomucosa, também conhecida como descolamento mucocutâneo, ocorre quando o a borda do segmento intestinal exteriorizado se desprende da pele que o circunda total ou parcialmente, com uma incidência relatada de 2 a $30 \%$ dos casos de complicações de estomias. Os principais fatores de risco são: tensão excessiva na sutura, infecção na linha de junção, uso regular de terapia com esteroide, radioterapia prévia, necrose da estomia, desnutrição, problemas na cicatrização da ferida operatória, equipamento coletor muito apertado na estomia, entre outros (PAULA; CESARETTI, 2014; VIEIRA, 2014; PAULA; MATOS, 2015).

O local onde há a separação cutaneomucosa deve ser avaliado para que se verifique a condição dos tecidos e a extensão do rompimento da linha de sutura. Quando a separação é superficial, o tratamento de escolha é o conservador, com cuidados locais para evitar o contato com fezes ou urina e a cicatrização ocorre por segunda intenção. Nos casos de separação cutaneomucosa total, torna-se necessária a reabordagem cirúrgica devido ao risco de contaminação da cavidade abdominal (PAULA; CESARETTI, 2014; PAULA; MATOS, 2015).

\section{Retração}

Na retração, a protrusão normal da estomia diminui ou desaparece do nível da pele do abdome, podendo ocorrer tanto no pós-operatório imediato ou tardio. É mais frequente nas estomias terminais e os principais fatores de risco são: distensão da parede do abdome, remoção precoce do suporte de alça, técnica de construção cirúrgica da estomia, necrose, separação cutaneomucosa da estomia e ganho de peso excessivo no período pós-cirúrgico (PAULA; CESARETTI, 2014; PAULA; MATOS, 2015; WOCN, 2016).

A retração é uma complicação que interfere no cuidado da estomia e pele periestoma, dificulta a aderência do equipamento coletor, permite o vazamento de efluentes ou urina e, normalmente, está associada a outras complicações como a dermatite periestoma e a estenose. O equipamento coletor convexo pode ser utilizado para o manejo da retração. Todavia, o uso deste material por período prolongado é contraindicado, sendo por vezes necessária a 
reabordagem cirúrgica para reposicionamento da estomia (PAULA; CESARETTI, 2014; PAULA; MATOS, 2015).

\section{Estenose}

A estenose é caracterizada pelo estreitamento ou contração da mucosa da estomia no nível da pele ou da fáscia, tornando difícil a drenagem do efluente. A incidência relatada de estenose é de 2 a 10\% dos casos de complicações pós-operatórias. Nas estomias intestinais, as fezes podem ter passagem explosiva pela estomia ou apresentarem formato afilado. Nas estomias urinárias, a urina pode ser eliminada em filete e com resíduo, ter sua saída diminuída e o paciente se queixa de dor na região lombar (PAULA; CESARETTI, 2014; VIEIRA, 2014; PAULA; MATOS, 2015).

Os fatores de risco para a ocorrência de estenose são: necrose da estomia, hiperplasia, formação de tecido cicatricial em excesso no nível da pele ou fáscia (em decorrência de lesão repetida na pele perístoma), construção cirúrgica da estomia, separação cutaneomucosa, irradiação do segmento intestinal e sutura inadequada da fáscia. $O$ tratamento desta complicação pode ser feito, dependendo do grau de estreitamento, com a dilatação digital/instrumental da estomia ou com a correção cirúrgica do estoma complicado (PAULA; CESARETTI, 2014; PAULA; MATOS, 2015).

\section{Hérnia paraestomal}

A hérnia paraestomal ou hérnia paraestomia ocorre devido à falha ou defeito da parede abdominal, levando a protrusão de vísceras abdominais através da abertura feita para a exteriorização do estoma, formando uma proeminência na região paraestomia. Pode estar relacionada à localização da estomia fora da bainha do músculo reto abdominal, fragilidade da musculatura abdominal causada pelo sedentarismo ou envelhecimento, obesidade ou caquexia, falha na fixação do mesentério da alça na parede lateral do abdome, pressão intraabdominal excessiva (causada pela tosse, choro, gestação, etc.) e o uso prolongado de corticosteroides (PAULA; CESARETTI, 2014; PAULA; MATOS, 2015; WOCN, 2016).

É comum que lactentes e crianças tenham hérnia paraestomal devido aos músculos abdominais estarem em desenvolvimento, sendo estes necessários para dar suporte ao estoma, além da pressão intra-abdominal causada pelo choro (WOCN, 2016)

O paciente que apresenta hérnia paraestomal enfrenta dificuldades que geram ansiedade e prejudicam sua qualidade de vida, como vazamento dos efluentes pela aderência 
prejudicada do equipamento coletor e dermatite periestoma, assim como outras complicações como obstrução, encarceramento ou estrangulamento do segmento exteriorizado. Para manejo da hérnia, os pacientes podem utilizar cinto elástico ou cinta abdominal e equipamento coletor com barreira flexível. O tratamento cirúrgico pode ser realizado para correção da hérnia em estomias intestinais ou urinárias por via laparoscópica, por correção local (técnica de plástica aponeurótica), mudança do local da estomia ou reforço com tela de material sintético (PAULA; CESARETTI, 2014; WOCN, 2016; PAULA; MATOS, 2015; SCHMIDT; HANATE, 2015).

\section{Prolapso de alça}

O prolapso é comumente entendido como "saída" da alça intestinal pela estomia, sendo mais frequente nas colostomias em alça. Os fatores de risco para o prolapso de alça são: abertura na parede do abdome maior que o diâmetro da alça intestinal a ser exteriorizada, fixação inadequada do intestino na parede do abdome, posicionamento da estomia fora do músculo reto do abdome, aumento da pressão abdominal no pós-operatório causada por exemplo por choro, tosse, gravidez e obesidade, entre outros (PAULA; CESARETTI, 2014; PAULA; MATOS, 2015; WOCN, 2016).

O estoma com prolapso pode apresentar edema, com aumento do risco de trauma da alça exteriorizada e potencial comprometimento do fluxo sanguíneo. Nos lactentes, pode ocorrer o prolapso enquanto a criança chora, reduzindo a protrusão quando a criança se acalma (WOCN, 2016).

O tratamento do prolapso pode ser feito com a redução digital, utilizando-se manobras delicadas, proteção da pele periestoma e da alça prolapsada, bem como o uso de dispositivo com diâmetro maior que o da estomia. No caso dos pacientes com estomia definitiva, a correção cirúrgica e o tratamento de escolha, assim como nos casos de isquemia do estoma, encarceramento ou estrangulamento, obstrução e incapacidade de realização das manobras de redução da estomia (PAULA; MATOS, 2015; PAULA; CESARETTI, 2014; WOCN, 2016).

\section{Dermatite periestoma}

A dermatite periestoma é uma complicação que afeta a pele circundante à estomia, causada pelo contato com efluente das estomias intestinais ou urinária, alergia aos componentes do equipamento coletor, infecção ou trauma mecânico, podendo ou não apresentar ruptura da integridade do sistema tegumentar. São classificadas em dermatite leve, 
moderada ou grave, a depender da profundidade e extensão das alterações na pele periestoma (PAULA; CESARETTI, 2015).

$\mathrm{Na}$ dermatite de contato, a lesão ocorre pela exposição direta da pele às substâncias irritantes que estão presentes nos efluentes, nos adesivos para fixação do equipamento coletor e nos produtos utilizados no local, como sabões e solventes. As enzimas digestivas, irritantes químicos e biológicos dos efluentes intestinais e urinários, bem como a umidade e os componentes dos sabões ou solventes provocam irritação na pele, enfraquecem a camada córnea da epiderme e alteram o $\mathrm{pH}$ da região, causando as lesões ao redor da estomia (PAULA; CESARETTI, 2015; WOCN, 2016). Pode ser classificada como leve, moderada ou intensa, dependendo das alterações tegumentares presentes na região periestoma, como grau de comprometimento, coloração e presença de exsudato (BORGES; RIBEIRO, 2015; PAULA; CESARETTI, 2015).

$\mathrm{Na}$ dermatite alérgica, ocorre uma resposta inflamatória local que resulta da hipersensibilidade ao componente químico da base adesiva do equipamento coletor que está em contato com a pele periestoma. Apresenta-se como uma erupção cutânea (rash cutâneo) limitada ao local de contato com componente que está provocando a alergia e o paciente normalmente refere ardor, queimação ou prurido (PAULA; CESARETTI, 2015; SCHMIDT; HANATE, 2015).

A dermatite por trauma geralmente está associada às situações relacionadas ao cuidado da estomia e pele periestoma, como remoção abrupta da bolsa coletora, limpeza exagerada da região periestoma, troca frequente do equipamento coletor, fricção ou pressão contínua exercida pelo clamp de fechamento da bolsa ou pela presilha de regulação do cinto elástico, má adaptação do equipamento coletor, podendo gerar abrasão da epiderme, esfolamentos, traumas na estomia ou tornar a região suscetível a lesões (PAULA; CESARETTI, 2015).

A dermatite por infecção é comumente causada por bactérias ou fungos, como o Staphiloccocus aureus e a Candida albicans, provocando foliculite ou candidíase na região periestoma. Na foliculite, a bactéria se instala nos folículos pilosos e os pelos são impedidos de crescer devido à sua remoção inadequada ou pela tração causada na remoção do equipamento coletor, provocando eritema e pústulas no local. Na candidíase, os fungos se proliferam no ambiente úmido e escuro sob o equipamento coletor, formando pústulas que podem evoluir para prurido, queimação, eritema e crostas. Fatores como alterações no sistema imune e microbiota natural do sistema tegumentar, radioterapia ou quimioterapia, diabetes 
mellitus, uso prolongado de antibióticos, favorecem o surgimento das dermatites por infecção nas pessoas com estomias (PAULA; CESARETTI, 2015; SCHMIDT; HANATE, 2015).

\subsection{Revisão Bibliográfica}

Com a finalidade de se conhecer as publicações relacionadas às complicações de estomias em crianças nos últimos dez anos, realizou-se uma revisão bibliográfica cuja coleta de dados se deu no período de agosto a setembro de 2016.

Para o desenvolvimento desta revisão bibliográfica foi adotada a metodologia proposta por Ganong (2005), compreendendo as seguintes etapas: definição do tema da revisão; formulação da questão norteadora; eleição da amostra após definição dos critérios de inclusão e exclusão; caracterização dos estudos, norteada por instrumento validado por Ursi (2005); análise dos resultados e discussão dos achados.

A busca eletrônica por produções científicas nacionais e internacionais se deu nas seguintes bases de dados: Indice Bibliográfico Español de Ciencias de la Salud (IBECS) e Bases de Dados de Enfermagem (BDENF), Medical Literature Analysis and Retrieval System Online (MEDLINE/PubMed) e Literatura Latino-Americana e do Caribe em Ciências da Saúde (LILACS).

A questão norteadora foi "Quais são as publicações que versam sobre as complicações de estomias em crianças?". Os descritores do DeCS (Descritores em Ciências da Saúde) e MeSH (Medical Subject Headings) foram utilizados na estratégia de busca combinados com operadores booleanos, sendo eles:

- Em português: “complicações pós-operatórias” AND estomia AND criança.

- Em inglês: "Postoperative complications" AND ostomy AND child.

Os critérios de inclusão foram: estudos originais disponíveis na íntegra gratuitamente e publicados entre 2006 e 2016, escritos em português, inglês e espanhol. Foram excluídos artigos que não estavam disponíveis para leitura de forma gratuita, aqueles que não tinham o texto completo e artigos repetidos nas bases de dados.

No início da busca, 82 artigos foram selecionados. Após leitura dos resumos, 76 artigos foram excluídos por não atenderem aos critérios de inclusão. Os seis artigos restantes foram analisados na íntegra, tendo seus dados extraídos e transcritos para o instrumento 
validado, o que possibilitou uma análise mais aprofundada e organização dos dados dos estudos.

Após transcrição dos dados para o instrumento, três artigos foram excluídos por também não atenderem aos critérios de inclusão definidos e por não responderem à pergunta de pesquisa, restando apenas três artigos ao final para compor a revisão integrativa da literatura (Quadro 3).

Quadro 3 - Classificação das publicações selecionadas para compor a revisão integrativa da literatura quando ao ano, autor e título.

\begin{tabular}{|c|c|c|l|c|}
\hline $\mathbf{N}^{\mathbf{0}}$ & $\begin{array}{c}\text { Ano de } \\
\text { publicação }\end{array}$ & Autores & \multicolumn{1}{|c|}{ Título } \\
\hline 1 & 2013 & Egito et al. & $\begin{array}{l}\text { Estado Nutricional de pacientes pediátricos } \\
\text { ostomizados. }\end{array}$ \\
\hline 2 & 2014 & Mabula et & $\begin{array}{l}\text { Hirschsprung's desease in children: a five year } \\
\text { experience at a University teaching hospital in } \\
\text { northwestern Tanzania. }\end{array}$ \\
\hline 3 & 2013 & $\begin{array}{c}\text { Stenström } \\
\text { et al. }\end{array}$ & $\begin{array}{l}\text { Appendicostomy in preschool children with anorectal } \\
\text { malformation: successful early bowel management } \\
\text { with a high frequency of minor complications. }\end{array}$ \\
\hline
\end{tabular}

A Escala do Oxford Centre for Evidence-Based Medicine (2009) foi utilizada para definir os níveis de evidência, sendo eles: 1A - revisão sistemática de ensaios clínicos controlados randomizados; 1B - ensaios clínicos controlados randomizados com intervalo de confiança estreito; 1C - estudos do tipo "tudo ou nada"; $2 \mathrm{~A}$ - revisão sistemática de estudos de coorte; 2B - estudos de coorte, incluindo os ensaios clínicos randomizados de menor qualidade; 2C - observação de resultados terapêuticos e estudos ecológicos; 3A - revisão sistemática de estudos do tipo caso-controle; 3B - estudos de caso-controle; nível 4 para relatos de caso, incluindo coorte ou caso-controle de menor qualidade; e nível 5 para opiniões de especialistas desprovidas de avaliação crítica ou aquelas baseadas em matérias básicas.

O Quadro 4 demonstra os artigos selecionados na revisão bibliográfica quanto aos objetivos, tipo de estudo e nível de evidência e Qualis CAPES dos periódicos onde foram publicados. 
Quadro 4 - Classificação das publicações segundo o objetivo, tipo de estudo, Qualis CAPES e nível de evidência.

\begin{tabular}{|c|l|l|c|c|}
\hline $\mathbf{N}^{\mathbf{0}}$ & Objetivos & Tipo de estudo & $\begin{array}{l}\text { Qualis } \\
\text { CAPES }\end{array}$ & Nível \\
\hline 1 & $\begin{array}{l}\text { Avaliar o estado nutricional de pacientes } \\
\text { pediátricos estomizados. }\end{array}$ & $\begin{array}{l}\text { Descritivo, do tipo } \\
\text { série de casos }\end{array}$ & B4 & 4 \\
\hline 2 & $\begin{array}{l}\text { Avaliar o resultado da apendicostomia em } \\
\text { crianças pré-escolares com malformação } \\
\text { anorretal, considerando os sintomas } \\
\text { intestinais e a frequência de complicações. }\end{array}$ & $\begin{array}{l}\text { Descritivo, do tipo } \\
\text { coorte retrospectiva }\end{array}$ & B2 & $2 \mathrm{~B}$ \\
\hline 3 & $\begin{array}{l}\text { Determinar as características clínicas e os } \\
\text { resultados do manejo da doença de } \\
\text { Hirschsprung, além de destacar os desafios } \\
\text { associados ao cuidado destes pacientes. }\end{array}$ & $\begin{array}{l}\text { Descritivo, do tipo } \\
\text { coorte prospectiva. }\end{array}$ & B4 & $2 \mathrm{~B}$ \\
\hline
\end{tabular}

Observou-se que a maioria dos artigos analisados $(\mathrm{n}=2)$ foram publicados por médicos e tem metodologia descritiva, o que evidencia a baixa publicação de enfermagem relacionada às complicações de estomias em crianças nos últimos anos.

Dos artigos selecionados para compor a amostra final desta revisão, percebeu-se que as complicações de estomias foram relatadas de maneira secundária, ou seja, não eram o foco principal dos estudos. Apesar disto, os estudos relataram as complicações mais frequentes em suas populações estudadas, sendo elas: escoriação de pele, prolapso da alça intestinal, hérnia paraestomia, sangramento no local da estomia, retração e estenose (EGITO et al, 2013; STENSTRÖM et al, 2013; MABULA et al, 2014).

Cabe destacar que os estudos selecionados para a revisão bibliográfica também foram utilizados para compor o referencial bibliográfico e subsidiar a discussão desta dissertação, somados a outras literaturas pertinentes referentes ao tema estudado. 


\section{MATERIAIS E MÉTODO}

\subsection{Tipo de estudo}

Trata-se de um estudo epidemiológico quantitativo, descritivo, de caráter prospectivo. Para Creswell (2010), a pesquisa quantitativa é um meio utilizado para testar teorias objetivas, examinando a relação entre variáveis que, por sua vez, podem ser medidas por instrumentos, para que os dados numéricos possam ser analisados por procedimentos estatísticos.

Segundo Hulley e colaboradores (2015), nos estudos de coorte prospectiva uma amostra de sujeitos é selecionada e então mede-se em cada sujeito as características que poderão predizer os desfechos subsequentes. Os sujeitos são seguidos no tempo por meio de medições periódicas dos desfechos de interesse do pesquisador.

A abordagem prospectiva impede que a aferição da variável preditora seja influenciada pelo desfecho ou pelo conhecimento da ocorrência deste, permitindo que sejam medidas variáveis importantes de maneira mais completa e acurada (HULLEY et al, 2015).

\subsection{Local do estudo}

O presente estudo foi realizado no Ambulatório de Atenção ao Estomizado de um hospital público do Distrito Federal. A Unidade Hospitalar escolhida é referência no atendimento cirúrgico neonatal e pediátrico, tanto ambulatorial quanto de urgência, dedicando 100\% de seus leitos ao Sistema Único de Saúde.

O Programa de Atenção ao Estomizado atende crianças e adolescentes estomizados desde 2002. Atualmente, possui 45 crianças e/ou adolescentes cadastrados e funciona nas quintas-feiras no período matutino (das 7 h às 11h) com uma média de 16 a 24 consultas mensais. Para ser atendido pelo Programa, a criança ou adolescente precisa ser estomizado (temporária ou definitivamente), ter idade entre zero a 18 anos, apresentar certidão de nascimento ou documento de identidade da criança e/ou adolescente, apresentar documento de identidade do responsável legal assim como o cartão de saúde com o respectivo número da Secretaria de Estado de Saúde (SES-DF) e comprovante de residência.

O Ambulatório de Atenção ao Estomizado tem uma estrutura física pequena, com armários para guarda dos materiais (equipamentos coletores e adjuvantes, gazes, algodão, entre outros), mesa com dois computadores para acesso aos prontuários eletrônicos e gavetas 
para guarda de materiais de escritório (formulários, canetas, etc.), três cadeiras, uma impressora, uma lixeira e uma maca para atendimento das crianças. As consultas são realizadas por duas enfermeiras e as crianças são atendidas individualmente (uma criança e seu acompanhante por vez), pela falta de espaço para atendimentos simultâneos. O Programa conta ainda com o suporte de outros profissionais de saúde, como nutricionistas, assistentes sociais e médicos, conforme preconiza a Portaria SAS/MS n 400 de 16 de novembro de 2009. As consultas destes profissionais ocorrem em dias e horários diferentes do dia de atendimento da equipe de enfermagem que atua no setor.

\subsection{População e amostra}

Devido à ausência de dados de prevalência sobre as complicações de estomias na população pediátrica que possibilitassem o uso de fórmulas de populações finitas para o cálculo amostral, optou-se pelo acompanhamento de todas as crianças que atendessem aos critérios de inclusão deste estudo durante o período de 6 meses.

A seleção da amostra foi constituída por conveniência, ou seja, não-aleatória, composta pelas crianças atendidas no Ambulatório de Atenção ao Estomizado de um hospital público do DF de 02 de fevereiro à 02 de agosto de 2016. No primeiro mês foi realizado estudo piloto com 10 crianças para verificar a adequação do instrumento e realizar ajustes, caso houvesse necessidade. Como não foi preciso ajustar o instrumento, as 10 crianças foram incluídas na amostra final do estudo.

Durante o período de coleta de dados houve três perdas ao acaso, ou seja, os representantes legais de duas crianças autorizaram verbalmente a participação delas no estudo, mas desistiram de assinar o TCLE após leitura do mesmo; e uma criança compareceu apenas uma vez ao ambulatório para consulta, sendo então as três crianças excluídas da amostra final do estudo. Ao término do período de coleta de dados, a amostra foi constituída por um total de 37 crianças.

\section{Critérios de inclusão da amostra:}

- Ser estomizado (estoma respiratório, gastrointestinal e/ou urinário);

- Ter idade entre zero e doze anos incompletos;

- Realizar pelo menos duas consultas no ambulatório do local de estudo. 
- Ter o Termo de Consentimento Livre e Esclarecido (TCLE) assinado pelos pais e/ou responsáveis.

\section{Critérios de exclusão da amostra:}

- Foram excluídos da amostra os indivíduos com idade igual ou superior a 12 anos e aqueles que os representantes legais se recusaram a assinar o TCLE ou retiraram o seu consentimento.

\subsection{Coleta de dados}

Os dados foram coletados pessoalmente pela pesquisadora, utilizando-se um instrumento elaborado especificamente para esta finalidade (APÊNDICE A), visando a caracterização da população do estudo e a identificação das complicações de estomias.

Os dados sociodemográficos e clínicos das crianças foram levantados por meio da análise dos prontuários eletrônicos, via trakcare, cujas variáveis foram sexo, procedência, data de nascimento, idade, diagnóstico médico e número de consultas realizadas no ambulatório.

Os dados referentes às estomias, às complicações e os fatores associados ao seu surgimento foram levantados também por meio da análise de prontuários eletrônicos (via trakcare) e por meio da observação direta das crianças durante as consultas ambulatoriais do local escolhido para realização estudo, cujas variáveis foram: tipos de estomia, causa geradora da estomia, tempo de permanência, caráter da estomia (definitiva ou temporária), previsão para reconstrução (em meses), orientação sobre a confecção da estomia, demarcação prévia, utilização de equipamento coletor, ocorrência de complicação, tipo de complicação, provável fator que ocasionou a complicação e tratamento empregado para resolução da complicação.

\subsection{Análise e categorização dos dados}

A análise estatística foi realizada utilizando-se o programa Statistical Package for the Social Sciences ${ }^{\circledR}$ (SPSS), versão 23.0 para Microsoft Windows ${ }^{\circledR}$, onde um banco de dados foi construído e as informações inseridas com dupla conferência para detecção precoce de erros na tabulação, facilitando a correção caso fosse necessária.

Para interpretação dos dados foi realizada análise estatística descritiva, onde as variáveis categóricas foram descritas por meio de frequência absoluta e relativa e as variáveis 
quantitativas por meio da média e desvio padrão. O desvio padrão é a medida da variação dos valores em torno da média; a média informa onde os valores do grupo estudado estão centrados, e o desvio padrão complementa esta informação, resumindo o agrupamento dos valores em torno da média (PEREIRA, 2002).

A análise estatística inferencial foi realizada utilizando-se o teste exato de Fisher ou o teste qui-quadrado para verificar a associação estatística entre a ocorrência de complicação e as variáveis: "sexo", "orientação prévia sobre a confecção da estomia", "demarcação prévia da estomia" e "utilização de equipamento coletor". Considerou-se um Intervalo de Confiança de $95 \%$ e o nível de significância de 5\%.

\subsection{Aspectos éticos e legais}

Os princípios éticos foram observados por meio das diretrizes e normas da Resolução do Ministério da Saúde no 466 de 12 de dezembro de 2012 que versa sobre ética em pesquisa envolvendo seres humanos (BRASIL, 2012).

O presente estudo foi então submetido à apreciação do Comitê de Ética em Pesquisa (CEP) da Fundação de Ensino e Pesquisa em Ciências da Saúde (FEPECS), responsável pela avaliação do mérito e relevância do desenvolvimento de projetos de pesquisa a serem desenvolvidos no âmbito da SES-DF e entidades vinculadas, sendo aprovado no dia 01 de fevereiro de 2016 pelo parecer consubstanciado $\mathrm{n}^{\circ}$ 1.399.909 (ANEXO C).

Os representantes legais das crianças atendidas no Ambulatório de Atenção ao Estomizado foram convidados na própria instituição onde foi realizado o estudo, individualmente e em ambiente reservado para autorizar a participação das crianças neste estudo. Nesta ocasião, foram explicados os objetivos do estudo, a metodologia e a importância da participação das crianças.

O TCLE (ANEXO A) foi apresentado antes da coleta de dados, informando os representantes legais das crianças sobre a participação voluntária, o sigilo, o anonimato e o acesso aos resultados da pesquisa, além da garantia de exclusão da criança do estudo a qualquer momento, se assim desejassem, sem qualquer tipo de prejuízo para o seu atendimento no ambulatório. O TCLE foi entregue em duas vias, onde ambas foram assinadas, ficando uma cópia com os pais e/ou responsáveis das crianças e outra com a pesquisadora. 


\subsection{Descrição do estudo}

Para descrição deste estudo foi utilizada a lista de verificação (checklist) da Iniciativa denominada Strengthening the Reporting of Observational Studies in Epidemiology (STROBE), criado visando melhorar a qualidade da apresentação dos resultados dos estudos observacionais. O checklist (ANEXO B) contém 22 itens relacionados a informações que devem estar presentes no título, resumo, introdução, método, resultados e discussão de estudos observacionais (MALTA et al, 2010).

A Iniciativa STROBE não pretende que suas recomendações sejam vistas como prescrições para a elaboração de desenhos ou condução de estudos observacionais. A intenção é fazer com que as descrições sejam elaboradas de maneira clara e objetiva, facilitando a leitura crítica destes estudos (MALTA et al, 2010). 


\section{Resultados}




\section{RESULTADOS}

\subsection{Perfil sociodemográfico e clínico das crianças com estomias}

O perfil sociodemográfico das 37 crianças que compuseram a amostra revelou que $32,4 \%$ delas eram do sexo feminino e $67,6 \%$ eram do sexo masculino. Em relação à procedência das crianças, 54\% eram do Distrito Federal, 43,3\% eram procedentes do Goiás e 2,7\% eram do estado de Minas Gerais. A Tabela 1 evidencia as características sociodemográficas das crianças estomizadas.

Tabela 1 - Distribuição das características sociodemográficas das crianças estomizadas de acordo com o sexo, idade, procedência e escolaridade. Brasília-DF, 2016.

\begin{tabular}{|c|c|c|c|c|}
\hline Características & $\mathbf{N}^{\mathbf{0}}$ & $\%$ & Média & Desvio Padrão \\
\hline \multicolumn{5}{|l|}{ Sexo } \\
\hline Masculino & 25 & 67,6 & - & - \\
\hline Feminino & 12 & 32,4 & & \\
\hline \multicolumn{5}{|l|}{ Idade } \\
\hline 2 meses a 12 meses & 25 & 67,6 & & \\
\hline 24 meses & 8 & 21,6 & 2,0 & 2,7 \\
\hline 36 meses & 4 & 10,8 & & \\
\hline \multicolumn{5}{|l|}{ Procedência } \\
\hline Distrito Federal & 20 & 54,0 & & \\
\hline Goiás & 16 & 43,3 & - & - \\
\hline Minas Gerais & 1 & 2,7 & & \\
\hline \multicolumn{5}{|l|}{ Escolaridade } \\
\hline Sem escolaridade & 25 & 67,6 & & \\
\hline Pré-escolar & 12 & 32,4 & - & - \\
\hline Total & 37 & 100 & & \\
\hline
\end{tabular}

Fonte: dados da pesquisa, 2016.

Sobre o diagnóstico médico das crianças, verifica-se o predomínio do megacólon congênito (35,2\%), também conhecido como doença de Hirschsprung, seguido do ânus imperfurado $(32,4 \%)$ conforme os dados apresentados no gráfico 1 . 


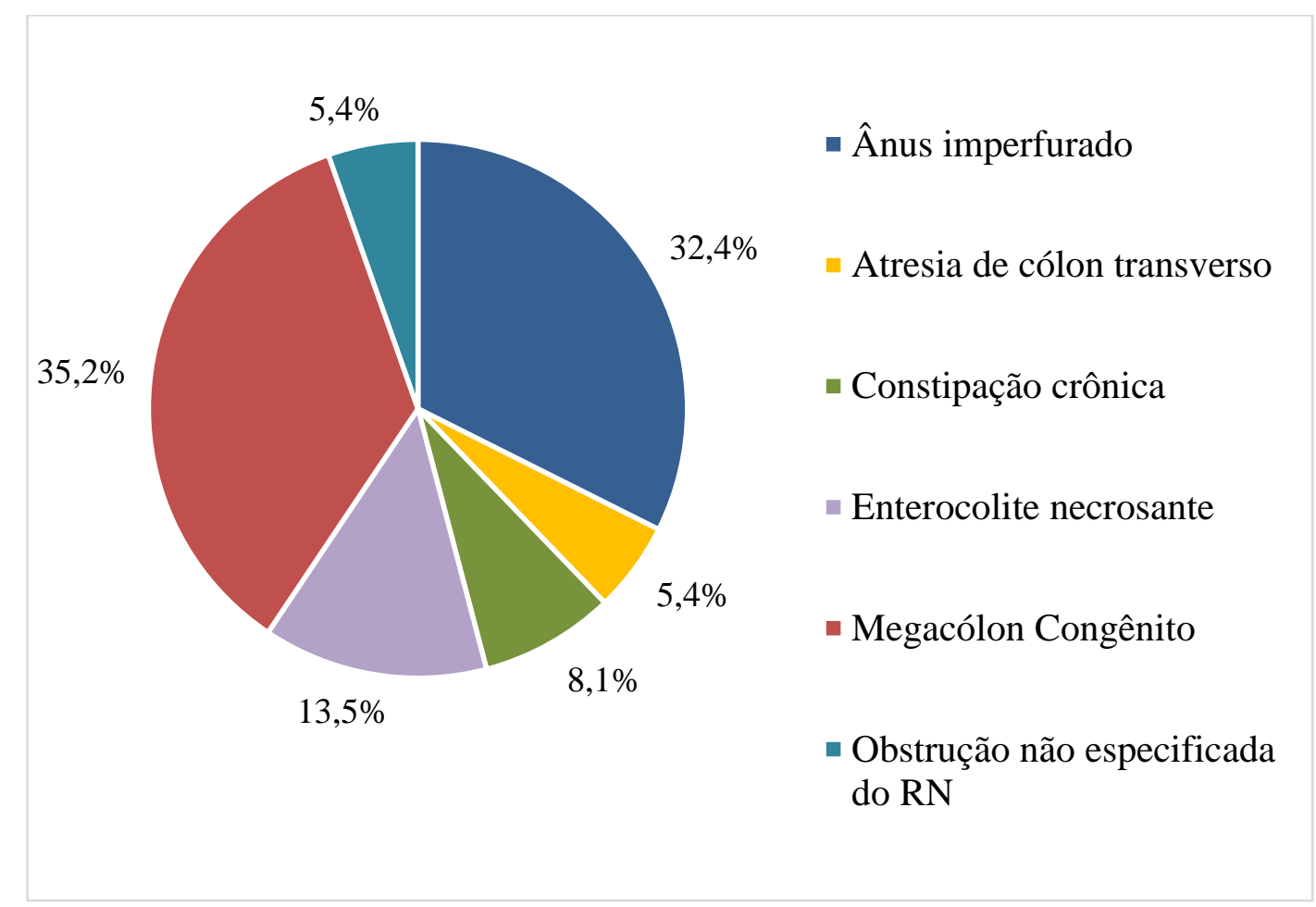

Gráfico 1 - Distribuição dos diagnósticos médicos das crianças com estomias atendidas no ambulatório. Brasília-DF, 2016.

Em relação ao número de consultas realizadas no Ambulatório de Atenção ao Estomizado, as crianças compareceram a uma média de 3,9 consultas de enfermagem durante o período de coleta de dados e permaneceram em média um ano e três meses estomizadas, conforme evidencia a Tabela 2. Em 91,9\% dos casos as crianças estavam acompanhadas pela mãe e $8,1 \%$ estavam acompanhadas pelo pai e mãe.

Tabela 2 - Medidas e valores das características das crianças segundo a idade, tempo de permanência da estomia e número de consultas de enfermagem. Brasília-DF, 2016.

\begin{tabular}{|c|c|c|c|c|c|c|c|c|c|}
\hline Características & Média & $\begin{array}{l}\text { Desvio } \\
\text { Padrão }\end{array}$ & $\begin{array}{c}\text { Valor } \\
\text { mínimo }\end{array}$ & $\begin{array}{c}1^{\circ} \\
\text { quartil }\end{array}$ & Mediana & $\begin{array}{c}3^{\circ} \\
\text { quartil }\end{array}$ & $\begin{array}{c}\text { Valor } \\
\text { máximo }\end{array}$ & $\begin{array}{l}\text { IC } \\
\text { inf }\end{array}$ & $\begin{array}{l}\text { IC } \\
\text { sup }\end{array}$ \\
\hline $\begin{array}{l}\text { Idade } \\
\text { (em meses) }\end{array}$ & 2,0 & 2,7 & 0,2 & 0,7 & 1,0 & 2,0 & 11,0 & 1,1 & 2,8 \\
\hline $\begin{array}{l}\text { Tempo de } \\
\text { permanência } \\
\text { da estomia }\end{array}$ & 1,3 & 1,8 & 0,2 & 0,4 & 0,9 & 1,2 & 11,0 & 0,7 & 1,8 \\
\hline $\begin{array}{l}\text { Número de } \\
\text { consultas de } \\
\text { enfermagem }\end{array}$ & 3,9 & 1,5 & 2,0 & 3,0 & 4,0 & 5,0 & 7,0 & 3,4 & 4,3 \\
\hline
\end{tabular}
Fonte: dados da pesquisa, 2016. 


\subsection{Características das estomias das crianças atendidas no ambulatório}

Das crianças estudadas, todas tiveram suas estomias classificadas como temporárias (100\%) no período da coleta de dados. Sobre a previsão para reconstrução do trânsito intestinal, 73\% das crianças ainda não tinham previsão $(n=27), 13,5 \%$ tinham previsão de 2 meses para reconstrução do trânsito intestinal $(n=5), 5,4 \%$ tinham previsão de 3 meses para reconstrução $(n=2), 5,4 \%$ tinham previsão de 4 meses para reconstrução $(n=2)$ e 2,7\% tinha previsão de 8 meses para reconstrução $(n=1)$. Não havia informações no prontuário sobre a previsão para reconstrução no caso das estomias urinárias ( vesieøstemia e cistestemia).

Em relação à causa que levou à confecção das estomias nas crianças estudadas, $73 \%$ tinham como causa as anomalias congênitas $(n=27), 13,5 \%$ das estomias foram confeccionadas por perfuração intestinal $(n=5), 8,1 \%$ tiveram como fator causal as obstruções intestinais $(n=3)$ e $5,4 \%$ foram confeccionadas devido ao distúrbio de motilidade provável $(\mathrm{n}=2)$.

Sobre o tipo de estomia, percebeu-se que a maioria das crianças tinha apenas um tipo de estomia confeccionada (86,5\%), 5,4\% tinham 2 tipos de estomias confeccionadas e $8,1 \%$ tinham um tipo de estomia acompanhada de fístula mucosa, como mostra o gráfico 2.

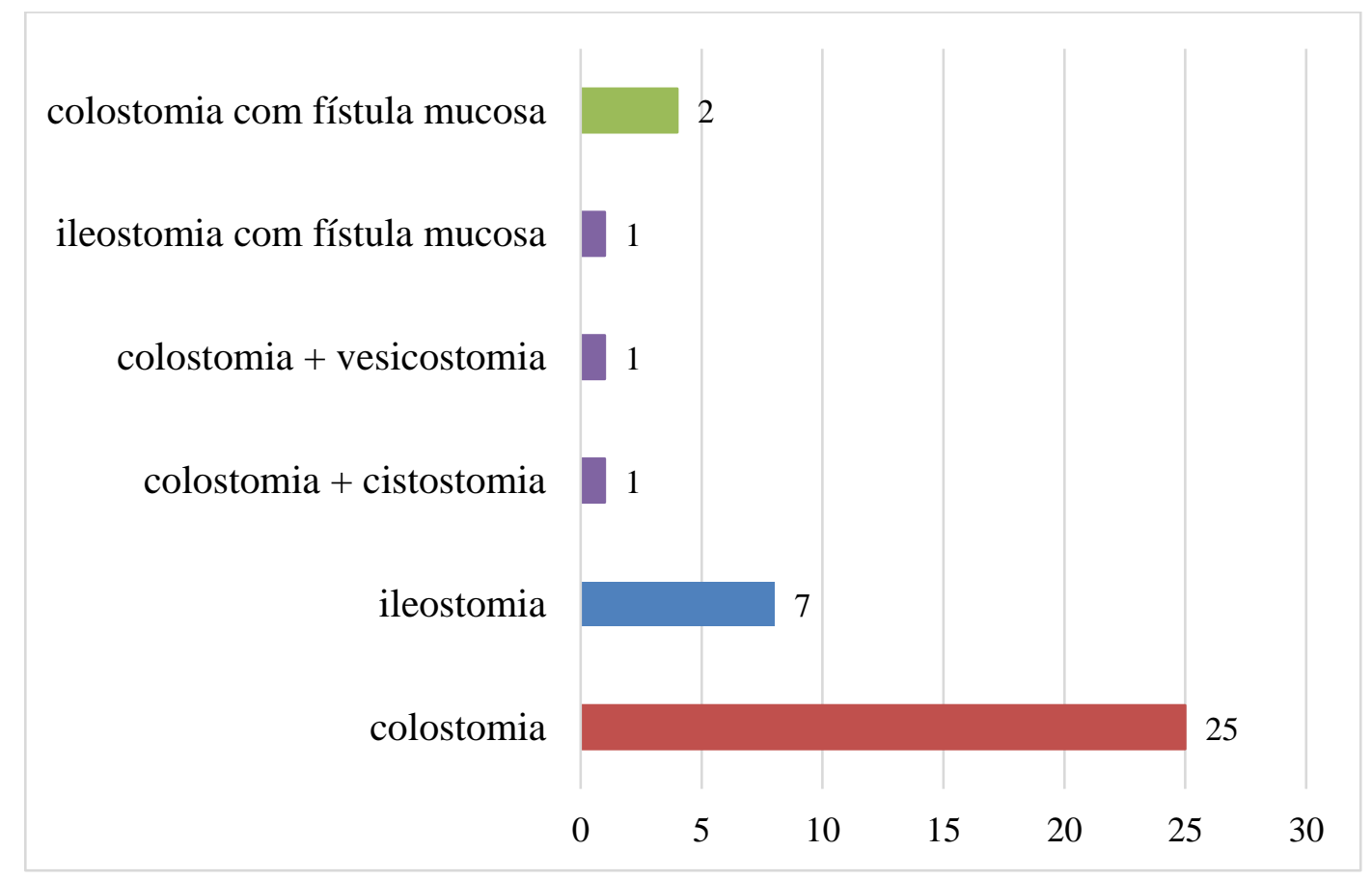

Gráfico 2 - Frequência absoluta das estomias de acordo com a localização. Brasília-DF, 2016. 
Os dados relacionados ao tempo de permanência da estomia demonstram que $24,4 \%$ das crianças estavam estomizadas há 12 meses $(n=9)$ e 18,9\% estavam estomizadas há 2 anos ou mais $(n=7)$, como mostra a Tabela 3.

Tabela 3 - Tempo de permanência das estomias nas crianças assistidas no ambulatório. Brasília-DF, 2016.

\begin{tabular}{lcc}
\hline \multicolumn{1}{r}{ Tempo } & Frequência absoluta & Frequência Relativa $(\boldsymbol{\%})$ \\
\hline 2 meses & 3 & 8,1 \\
3 a 4 meses & 6 & 16,2 \\
5 a 6 meses & 3 & 8,1 \\
7 a 8 meses & 6 & 16,2 \\
10 a 11 meses & 3 & 8,1 \\
12 meses & 9 & 24,4 \\
2 anos ou mais & 7 & 18,9 \\
\hline Total & $\mathbf{3 7}$ & $\mathbf{1 0 0}$ \\
\hline
\end{tabular}

Fonte: dados da pesquisa, 2016.

Em relação à orientação prévia sobre a confecção da estomia no período préoperatório, 70,2\% dos pais e/ou responsáveis das crianças relataram ter recebido orientações (n=26) e 29,8\% relataram não ter recebido orientações antes do procedimento cirúrgico $(\mathrm{n}=11)$. Sobre o procedimento de demarcação das estomias, a maioria das crianças não teve o local de confecção da estomia demarcado $(97,3 \%)$ e $2,7 \%$ teve o local demarcado antes da cirurgia.

Sobre a utilização do equipamento coletor, 59,5\% das crianças utilizavam equipamento coletor com frequência $(n=22)$ e 40,5\% não utilizavam equipamento coletor com frequência $(n=15)$. Durante o período de coleta de dados, oito crianças realizaram o procedimento de reconstrução do trânsito intestinal e apenas uma delas precisou confeccionar a estomia intestinal novamente por complicações pós-operatórias relacionadas à doença de base.

\subsection{Complicações de estomias e os fatores associados}

Neste estudo, 21 crianças apresentaram complicações de estomias, sendo que em algumas delas ocorreu mais de um tipo de complicação. A incidência cumulativa de complicação de estomia neste estudo foi de $56,7 \%$. 
A complicação mais frequente foi a dermatite de contato ( $76 \%$ dos casos), como mostra a Tabela 4. Sobre o fator que ocasionou as complicações, $76 \%$ se deu pelo contato da pele com efluentes $(n=19), 8 \%$ surgiu por hipersensibilidade à base adesiva do equipamento coletor $(n=2), 8 \%$ ocorreu pela técnica de construção cirúrgica da estomia $(n=2)$ e $8 \%$ se deu pelo aumento da pressão intra-abdominal $(n=2)$.

Tabela 4 - Tipos de complicações de estomias nas crianças estudadas. Brasília-DF, 2016.

\begin{tabular}{lcc}
\hline \multicolumn{1}{c}{ Tipos de complicações } & Frequência absoluta & Frequência Relativa (\%) \\
\hline Dermatite de contato & 19 & 76,0 \\
Dermatite alérgica & 2 & 8,0 \\
Retração & 2 & 8,0 \\
Prolapso de alça & 1 & 4,0 \\
Hérnia paraestomia & 1 & 4,0 \\
\hline Total & $\mathbf{2 5}$ & $\mathbf{1 0 0}$ \\
\hline
\end{tabular}

Fonte: dados da pesquisa, 2016.

Em relação ao tratamento empregado para resolução da complicação, em $100 \%$ dos casos foram utilizados produtos cuja finalidade era fornecer uma barreira protetora para a pele periestoma e/ou tratar as dermatites (protetores cutâneos sintéticos com apresentação em pó ou pasta).

As variáveis "sexo" e "ocorrência de complicação", bem como "orientação prévia sobre a confecção da estomia" e "ocorrência de complicação" tiveram suas frequências absolutas comparadas e associadas por meio do teste qui-quadrado (Tabelas 5 e 6). Não houve associação estatística significativa.

Tabela 5 - Associação entre o sexo das crianças e a ocorrência de complicação. Brasília-DF, 2016.

\begin{tabular}{|c|c|c|c|c|}
\hline & & \multicolumn{2}{|c|}{$\begin{array}{c}\text { Ocorrência de complicação de } \\
\text { estomia }\end{array}$} & \multirow[t]{2}{*}{ Total } \\
\hline & & Sim & Não & \\
\hline \multirow[t]{3}{*}{ Sexo } & Masculino & 15 & 10 & 25 \\
\hline & Feminino & 6 & 6 & 12 \\
\hline & Total & 21 & 16 & 37 \\
\hline
\end{tabular}

$(\mathrm{p}=0,565) ; \mathrm{RR}=1,500(0,375-5,998)$

Fonte: dados da pesquisa, 2016. 
Tabela 6 - Associação entre orientação prévia sobre a confecção da estomia e a ocorrência de complicação. Brasília-DF, 2016.

\begin{tabular}{l|l|c|c|c}
\hline \multirow{2}{*}{} & \multicolumn{2}{|c}{$\begin{array}{c}\text { Ocorrência de complicação de } \\
\text { estomia }\end{array}$} & \multirow{2}{*}{ Total } \\
\cline { 3 - 5 } \multicolumn{2}{l|}{} & Sim & Não & \\
\hline \multirow{2}{*}{$\begin{array}{l}\text { Orientação prévia sobre a } \\
\text { confecção da estomia }\end{array}$} & Sim & 15 & 12 & 27 \\
\cline { 2 - 5 } & Não & 6 & 4 & 10 \\
\hline
\end{tabular}

$(\mathrm{p}=0,809) ; \mathrm{RR}=0,833(0,191-3,644)$

Fonte: dados da pesquisa, 2016.

Por meio da aplicação do teste exato de Fisher, as variáveis "demarcação prévia da estomia" e "ocorrência de complicação" tiveram suas frequências absolutas cruzadas nas tabelas de contingência (Tabela 7). Não houve associação estatística significativa.

Tabela 7 - Associação entre demarcação prévia da estomia e a ocorrência de complicação. Brasília-DF, 2016.

\begin{tabular}{|c|c|c|c|c|}
\hline & \multicolumn{2}{|c|}{$\begin{array}{l}\text { Ocorrência de complicação de } \\
\text { estomia }\end{array}$} & \multirow[t]{2}{*}{ Total } \\
\hline & & Sim & Não & \\
\hline \multirow{2}{*}{$\begin{array}{l}\text { Demarcação prévia da } \\
\text { estomia }\end{array}$} & Sim & 0 & 1 & 1 \\
\hline & Não & 21 & 15 & 36 \\
\hline & Total & 21 & 16 & 37 \\
\hline
\end{tabular}

$(\mathrm{p}=0,432) ; \mathrm{RR}=2,400(1,631-3,532)$

Fonte: dados da pesquisa, 2016.

As variáveis "utilização de equipamento coletor" e "ocorrência de complicação" tiveram suas frequências absolutas cruzadas na tabela de contingência e comparadas por meio do teste qui-quadrado (Tabela 8). Houve associação estatística significativa.

Tabela 8 - Associação entre utilização de equipamento coletor e a ocorrência de complicação. Brasília-DF, 2016.

\begin{tabular}{l|l|c|c|c}
\hline \multirow{2}{*}{\multicolumn{2}{c|}{}} & \multicolumn{2}{|c}{$\begin{array}{c}\text { Ocorrência de complicação de } \\
\text { estomia }\end{array}$} & \multirow{2}{*}{ Total } \\
\cline { 3 - 5 } & Sim & Não & \\
\hline \multirow{2}{*}{$\begin{array}{l}\text { Utilização de equipamento } \\
\text { coletor }\end{array}$} & Sim & 9 & 13 & 22 \\
\cline { 2 - 5 } & Não & 12 & 3 & 15 \\
\hline \multicolumn{2}{r|}{ Total } & $\mathbf{2 1}$ & $\mathbf{1 6}$ & $\mathbf{3 7}$ \\
\hline
\end{tabular}

$(\mathrm{p}=0,018) ; \mathrm{RR}=0,173(0,038-0,795)$

Fonte: dados da pesquisa, 2016. 


\section{DISCUSSÃO}

O perfil sociodemográfico da amostra estudada revelou a predominância de crianças do sexo masculino e procedentes de regiões administrativas do Distrito Federal, corroborando dados de outra pesquisa anteriormente realizada (MONTEIRO et al, 2014). A faixa etária da maior parte das crianças que compuseram a amostra ficou compreendida entre 2 meses e 1 ano de idade.

Em relação ao diagnóstico médico das crianças estudadas, os mais frequentes foram os referentes às malformações congênitas, como o megacólon congênito e o ânus imperfurado, sendo estes diagnósticos os que comumente levam as crianças a serem estomizadas (CARVALHO, 2003; EGITO et al, 2013; MABULA et al, 2014; STENSTRÖM et al, 2013; MONTEIRO et al, 2014).

O Megacólon congênito ou doença de Hirschsprung é uma doença multifatorial que resulta da ausência de migração das células da crista neural para o intestino grosso durante o desenvolvimento da criança intraútero, gerando uma inexistência de plexos nervosos no cólon e, consequentemente, ausência de motilidade no segmento acometido causando obstrução intestinal (MABULA et al, 2014; DINIZ et al, 2016). Normalmente o megacólon congênito é diagnosticado no período neonatal e o bebê apresenta sinais e sintomas como passagem tardia do mecônio (por um período superior a 24 horas), abdome distendido e episódios de vômito (TJADEN; TRAINOR, 2013). Uma estomia é então confeccionada para restabelecer o trânsito intestinal e permitir que a criança cresça e se desenvolva adequadamente.

A anomalia anorretal conhecida como ânus imperfurado envolve o ânus e o reto, podendo estar associada a defeitos em outras estruturas ou sistemas, como por exemplo na coluna vertebral, trato urinário ou genital, e a criança não apresenta a abertura anal que deveria. Geralmente uma colostomia é confeccionada ainda no período neonatal e, em média quatro a seis meses depois, uma fístula anal é confeccionada para posterior reabordagem cirúrgica e reconstrução do trânsito intestinal (MOENNE, 2003; MELO; KAMADA, 2011; ALAMO et al, 2013).

Todas as crianças que compuseram a amostra deste estudo estavam cadastradas no Programa de Atenção ao Estomizado da SES-DF e realizaram uma média de 3,9 consultas no ambulatório durante o período de coleta de dados, permitindo que tivessem acesso mensalmente a cerca de 10 a 20 equipamentos coletores para estomias de uma ou duas peças, 
adjuvantes (placas de hidrocoloide extrafino, resinas sintéticas em pó ou em pasta) e outros materiais, como gazes não estéreis.

As crianças compareciam às consultas acompanhadas, na maioria das vezes, pelas mães, que são consideradas as principais cuidadoras. Este fato que é recorrente, principalmente no universo da pediatria, é destacado também em outros estudos (SECCANI et al, 2007; SAMPAIO et al, 2009; MONTEIRO et al, 2016). Também foi possível observar a presença diminuída dos pais nas consultas e, pelo relato das mães, da pouca participação destes no cuidado domiciliar prestado à estas crianças.

A mãe é percebida como principal cuidadora das crianças, incluindo aquelas dependentes de tecnologias, gerando uma sobrecarga física e emocional. No entanto, a condição de saúde da criança, seja temporária ou definitiva, acaba interferindo em toda a dinâmica familiar, uma vez que a criança com estomia tem mudanças em seu dia-a-dia devido as alterações fisiológicas, psicológicas e sociais, o que pode gerar nos familiares sentimentos de irritabilidade, frustração, ansiedade e culpa. Deste modo, é importante que os profissionais de saúde também percebam as necessidades dos familiares destas crianças, ampliando os espaços de acolhimento e interação, recebendo as dúvidas e permitindo a manifestação das inquietações (LEITE; CUNHA, 2007; POLLETO et al, 2011; MONTEIRO et al, 2016; PELLEGRINO, 2014).

O Ambulatório de Atenção ao Estomizado do hospital onde foi realizado o estudo funciona em um dia da semana (quinta-feira), apenas no turno matutino (nos outros dias da semana o espaço funciona para atender as demandas da Comissão de Resíduos do hospital) e, durante a coleta de dados desta pesquisa, percebeu-se que o foco maior dos atendimentos estava no fornecimento de equipamentos coletores e adjuvantes. As enfermeiras que atuam no ambulatório não são especialistas em Estomaterapia, realidade também de outros ambulatórios de assistência ao estomizado do DF, evidenciando a carência de profissionais especializados na assistência direta às pessoas com estomias.

Cabe ressaltar que os profissionais de saúde que atuam nos ambulatórios de atenção ao estomizado não devem restringir suas consultas apenas à distribuição de materiais para os pacientes com estomias. A Portaria do Ministério da Saúde no 400 de 2009 preconiza que na Atenção Básica sejam realizadas orientações para o autocuidado, para a prevenção e tratamento de complicações nas estomias, além do fornecimento de equipamentos coletores e adjuvantes de segurança e proteção. A referida portaria ressalta também a importância da 
educação continuada dos profissionais na atenção básica, de média e alta complexidade para que seja possível prestar uma atenção adequada às pessoas com estomas (BRASIL, 2009).

Em relação às características das estomias das crianças, houve predomínio das colostomias (com ou sem fístula mucosa) em relação às outras estomias, como por exemplo as ileostomias, corroborando dados de outros estudos (SECCANI et al, 2007; EGITO et al, 2013; MONTEIRO et al, 2014; MABULA et al, 2014). Também houve crianças com mais de uma estomia, fator bastante comum nesta clientela (MONTEIRO et al, 2014).

Todas as crianças estudadas tiveram suas estomias classificadas como temporárias, mas $73 \%$ delas não tinham previsão para reconstrução definidas pelos médicos. O caráter temporário das estomias também é comum na população pediátrica, sendo estas normalmente confeccionadas no período neonatal, e seu tempo de permanência dependerá de fatores como a doença de base da criança, o fator causal que gerou a confecção da estomia e sua evolução clínica (MONTEIRO et al, 2014; MURAGAKI; RAICHER, 2014; KAYO et al, 2015).

A maioria dos familiares relatou ter recebido orientações pré-operatórias sobre o procedimento de confecção das estomias nas crianças. Todavia, declararam no momento da coleta de dados que a ênfase das orientações estava na doença de base da criança e em seu tratamento, não se abordando as questões psicossociais, educacionais e o impacto da condição de ser estomizado na vida da criança e de sua unidade familiar.

Em relação ao procedimento de demarcação das estomias, 97,3\% das crianças não tiveram o local do estoma demarcado antes de sua confecção, confirmando dados da literatura que justificam a não demarcação do local devido, na maioria das vezes, ao caráter de urgência das cirurgias de confecção do estoma. No entanto, quando a cirurgia tem caráter eletivo, as crianças são internadas previamente para preparo do cólon e, deste modo, este momento pode ser utilizado para realizar a demarcação do local da estomia, oferecer informações sobre a cirurgia, o tipo de estomia que será confeccionada, informações sobre o cuidado (vestimenta, higiene corporal, manejo dos equipamentos coletores e adjuvantes, etc.) e as alterações na imagem corporal e na dinâmica familiar. O brinquedo terapêutico, dramatizações, ludoterapia, entre outros, são recursos que podem ser utilizados para aproximação e criação de vínculo entre a equipe de enfermagem, as crianças estomizadas e seus familiares (KAYO et al, 2015; PELLEGRINO, 2014). 
Mesmo não havendo associação estatística significativa entre as variáveis “demarcação da estomia" e "ocorrência de complicação" ( $\mathrm{p}=0,432)$ nesta pesquisa, é sabido que a demarcação possibilita a facilidade de higiene da estomia e região periestoma, além de assegurar uma melhor adaptação do equipamento coletor e a prevenção de complicações no local (CESARETTI et al, 2015; PERSON, 2012; SANTOS et al, 2007; WOCN, 2014).

Observou-se neste estudo que a maioria das crianças $(n=22)$ faz uso do equipamento coletor com frequência para conter os efluentes, seguindo assim as recomendações descritas na literatura, evitando a contaminação da ferida operatória (no intra e pós-operatório imediato ou mediato) e protegendo a pele periestoma (KAYO et al, 2015; PELLEGRINO, 2014; WOCN, 2011). No entanto, mesmo utilizando o equipamento coletor, algumas crianças apresentaram dermatite periestoma de contato ou alérgica.

Quando as variáveis "uso de equipamento coletor" e "ocorrência de complicações" foram comparadas e associadas por meio de teste estatístico, houve significância $(p=0,018)$ e, deste modo, acredita-se que o uso inadequado ou a não utilização do equipamento coletor pode interferir diretamente no surgimento das complicações. É importante que os profissionais de saúde, principalmente os enfermeiros, conheçam os materiais disponíveis no mercado para o cuidado com as estomias, pois estes apresentam tamanhos variados de equipamentos coletores (permitindo a sua utilização na população pediátrica), com diferentes composições, com ou sem adesivo microporoso, de uma ou duas peças, proporcionando boa aderência da placa adesiva e proteção da pele periestoma, cicatrização de lesões superficiais e conforto (PELLEGRINO, 2014; CESARETTI et al, 2015).

Assim como é realizado na população adulta, o teste do equipamento coletor para verificar reações de hipersensibilidade pode ser feito na população pediátrica, de preferência no pré-operatório, para que o enfermeiro e os pais e/ou responsáveis conheçam qual o material se adapta melhor às necessidades da criança (KAYO et al, 2015; PELLEGRINO, 2014).

Na pediatria, é importante levar em consideração a pele da criança ao escolher os materiais para o cuidado com as estomias, pois esta possui particularidades que a difere da pele dos adultos. Nos recém-nascidos, a pele é mais fina, menos pilosa e apresenta menor coesão entre a epiderme e a derme, tornando-a suscetível às lesões. Nas crianças a partir de 1 ano de idade, as características da pele são similares a pele do adulto, mas há ausência da atividade das glândulas apócrinas sudoríparas. Pela característica particular da pele das 
crianças, ocorre maior absorção de componentes e sensibilidade a pró-alergênicos e irritantes. Portanto, os produtos aplicados na pele devem ser clinicamente testados e não agressivos (HOCKENBERRY; WILSON, 2011; YAMADA, 2015).

Chamou a atenção o fato de algumas crianças $(n=15)$ não utilizarem com frequência o equipamento coletor nas estomias, fazendo uso de outros materiais (como fraldas descartáveis e gazes não estéreis) para conter os efluentes, bem como de uma pasta caseira para proteção da pele periestoma (preparada pelos próprios cuidadores) composta por amido de milho, óxido de zinco e óleo enriquecido com ácidos graxos essenciais. Percebeu-se durante as consultas, que comumente a consistência da pasta caseira dificultava sua remoção da pele das crianças, protegendo o tegumento do contato direto com os efluentes e evitando a ocorrência de dermatite de contato em alguns casos, mas podendo gerar outras complicações, como as dermatites por trauma, devido a fricção excessiva durante a remoção do produto.

A SOBEST (2016) diz em seu Código de Ética, no tópico que trata sobre os aspectos éticos envolvendo a assistência da Estomaterapia, que o desenvolvimento de novas abordagens terapêuticas pode ser aplicado, desde que respeite a legislação vigente e as diretrizes nacionais para pesquisas envolvendo seres humanos, assim como a utilização de materiais, equipamentos e medicamentos deve levar em consideração sua eficácia, efetividade, eficiência, legitimidade, equidade, aceitabilidade e otimização.

Neste estudo, 56,7\% das crianças apresentaram complicações de estomias, sendo a dermatite de contato a complicação mais frequente, ocorrendo em $76 \%$ dos casos. Outras complicações estiveram presentes, como a dermatite alérgica, retração, prolapso de alça e hérnia paraestomia. Dados semelhantes são encontrados em outros estudos nacionais e internacionais (CARVALHO, 2003; EGITO et al, 2013; STENSTRÖM et al, 2013; MABULA et al, 2014), bem como na literatura relacionada a Estomaterapia (RNAO, 2009; MURAGAKI; RAICHER, 2014; ROCHA; VELHOTE, 2015; PAULA; CESARETTI, 2015; WOCN, 2016).

A dermatite periestoma causada pelo contato prolongado da pele com os efluentes (urina, fezes, conteúdo gástrico) prejudica o processo de reabilitação do paciente estomizado e aumenta os custos com o manejo da estomia, uma vez que interfere na aderência do equipamento coletor, tornando necessária a utilização de um número maior de bolsas coletoras e adjuvantes, além de causar dor devido ao processo inflamatório local e a ruptura da integridade da pele (BORGES; RIBEIRO, 2015; PAULA; CESARETTI, 2015). 
O tratamento empregado em todas as crianças que apresentaram complicações de estomias, independente do tipo de complicação, foi a resina sintética com apresentação em pó ou pasta. Alguns cuidadores relataram utilizar a resina sintética em pó mesmo na ausência da dermatite, com a finalidade de "prevenir" o surgimento de lesões.

A resina sintética em pó é composta por carboximetilcelulose sódica, goma xantina e goma guar, gelatina e pectina, tendo o uso indicado para os casos de maceração da pele periestoma e dermatite de contato. A resina sintética em pasta é composta por polímeros hidrofílicos, como carboximetilcelulose sódica, gelatina, pectina, poliisobutileno, com ou sem álcool, indicada para preencher irregularidades da região periestoma e prevenir a infiltração dos efluentes entre o sistema coletor em uso e a pele (diminuindo o risco de lesão nesta área), ajudando também na fixação da placa adesiva da bolsa coletora (PELLEGRINO, 2014; CESARETTI et al, 2015).

Para prevenção da dermatite periestoma, alguns cuidados podem ser tomados, como a manutenção da região periestoma limpa e livre de umidade. A limpeza pode ser feita com água morna e sabão neutro (ou levemente ácido), com movimentos suaves para prevenir o trauma mecânico ou irritação pela fricção da pele. Os resíduos da placa adesiva da bolsa coletora ou de outros adesivos devem ser removidos, bem como os resíduos dos efluentes, devendo a troca do equipamento coletor ser feita sempre que houver necessidade (PAULA; CESARETTI, 2015).

É importante que o plano terapêutico do enfermeiro tenha como base o fator causal da dermatite, os materiais habitualmente utilizados e a revisão das ações de cuidado realizadas pelo paciente e/ou cuidador, assim como a avaliação frequente da região periestoma (PAULA; CESARETTI, 2015; WOCN, 2016), para que a assistência seja prestada de maneira integral e individualizada, levando em consideração as necessidades e as particularidades de cada criança, possibilitando assim a escolha do equipamento coletor e adjuvantes apropriados.

Os princípios básicos do tratamento das complicações de estomias na pediatria não diferem daqueles relacionados às complicações nos adultos, respeitadas as particularidades de cada faixa etária (KAYO et al, 2015). Em relação às outras complicações que surgiram neste estudo, é importante salientar que estas nem sempre possuem causas em comum e, deste modo, os fatores geradores destas complicações também devem ser investigados e considerados pelo enfermeiro capacitado ou o estomaterapeuta, em conjunto com outros profissionais de saúde quando necessário, para resolução do problema. 
Diante do exposto, torna-se fundamental a manutenção da integridade da pele periestoma e da estomia para o processo de reabilitação da pessoa estomizada (CESARETTI; SANTOS, 2014). A educação continuada das crianças e seus familiares é fator importante na assistência prestada, uma vez que facilita a adaptação à nova condição e contribui para a prevenção das complicações de estomias, influenciando diretamente na qualidade de vida destes pacientes.

Como limitações do estudo, tem-se o tamanho reduzido da amostra $(n=37)$ e o fato de que este estudo, por ter sido realizado apenas em um setor, abrangeu as crianças apenas com estomias intestinais e urinárias (população atendida no ambulatório), não sendo possível conhecer as complicações referentes a outros tipos de estomias na população pediátrica do hospital escolhido para realização da pesquisa. Além disso, não foi possível observar pessoalmente todas as consultas das crianças, pois algumas delas compareciam no ambulatório de atenção ao estomizado em dias ou horários contrários àquele determinado para atendimento desta clientela, ficando a coleta dos dados das crianças em algumas consultas restritas apenas ao registro feito pelas enfermeiras no prontuário. 
Conclusão 


\section{CONCLUSÃO}

O objetivo deste estudo foi conhecer a incidência das complicações de estomias e os fatores associados à estas complicações nas crianças atendidas no Ambulatório de Atenção ao Estomizado de um hospital público do Distrito Federal. Por meio do instrumento utilizado para a coleta de dados foi possível alcançar a meta, bem como conhecer o perfil sociodemográfico das crianças estudadas.

As crianças que fizeram parte deste estudo apresentaram algumas características que são consideradas fatores de risco para o desenvolvimento de complicações, como a idade (pelas características de seu sistema tegumentar), má adaptação ou não utilização do equipamento coletor e a ausência de demarcação do local da estomia. Considera-se essencial que os enfermeiros busquem a capacitação na área da Estomaterapia para atender esta clientela e que a assistência de enfermagem inclua a avaliação das condições clínicas da criança, a demarcação do local onde será confeccionada a estomia, o ensino do autocuidado (para as crianças maiores) ou do cuidado que será prestado pelos pais e/ou responsáveis (no caso das crianças menores), assim como a identificação dos fatores que podem levar à ocorrência das complicações e manejo adequado destas.

É importante destacar a necessidade de consultas de enfermagem no pré ou pósoperatório voltadas não só para o cuidado da estomia e da região periestoma em si, mas que também envolvam questões psicológicas, sociais, culturais, espirituais, entre outras, tornando possível a realização de uma assistência que responda às necessidades físicas e emocionais da criança com estomia e de seus familiares.

Observou-se que há um número reduzido de estudos nacionais e internacionais sobre a incidência ou prevalência de complicações de estomias na população pediátrica. Desta forma, espera-se que os resultados desta pesquisa possam ser utilizados para a criação de protocolos e para melhorar o atendimento das crianças estomizadas, de modo que as intervenções sejam planejadas e executadas incluindo a educação permanente das crianças e seus familiares e a utilização adequada dos recursos materiais, com adequada provisão e previsão de equipamentos coletores e adjuvantes, contribuindo para a reabilitação destas crianças e, consequentemente, para a melhora em sua qualidade de vida.

Sugere-se que mais estudos com a temática proposta nesta dissertação sejam realizados, de preferência com uma amostragem maior, em outros ambulatórios ou hospitais 
do DF, com coleta de dados em um período superior a 6 meses e incluam estomias no trato urinário, intestinal e respiratório, a fim de que se explore amplamente a questão das complicações de estomias nas crianças em seguimento ambulatorial ou em outros setores onde se atenda esta clientela específica. 
Referências 


\section{REFERÊNCIAS}

ALAMO, L. Anorectal malformations: finding the pathway out of the labyrinth. Radiographics, 2013; march-april, 33(2): 491-513.

ASSOCIAÇÃO BRASILEIRA DE ESTOMATERAPIA (SOBEST). Competências do Enfermeiro Estomaterapeuta (ET) ou do Enfermeiro Pós-graduado em Estomaterapia (PGET). Rev Estima, 2008; 6(1): 33-43.

ASSOCIAÇÃO BRASILEIRA DE ESTOMATERAPIA (SOBEST). Diretrizes éticas para o exercício da Estomaterapia no Brasil. SOBEST, 2016. Disponível em: http://sobest.org.br/arquivos/codigo-de-etica-sobest.pdf.

ASSOCIAÇÃO BRASILEIRA DE OSTOMIZADOS (ABRASO). Declaração do direito dos ostomizados. Disponível em: http://www.abraso.org.br/declaracao_ioa.htm. Acesso em: 25 de outubro de 2016.

BANDEIRA, R.C.F.; GUIMARÃES, G.C. Colostomia e ileostomia úmidas: indicações, técnicas e cuidados. In: SANTOS, V.L.C.G.; CESARETTI, I.U.R. Assistência em Estomaterapia: cuidando de pessoas com estomia. 2. ed. São Paulo: Editora Atheneu, 2015 .

BERTEVELLO, P.L.; SOBREIRA, R.S.; MORAIS, P.A.B. Gastrostomia: indicações, técnicas e cuidados no adulto. In: SANTOS, V.L.C.G.; CESARETTI, I.U.R. Assistência em Estomaterapia: cuidando de pessoas com estomia. 2. ed. São Paulo: Editora Atheneu, 2015.

BRASIL. Ministério da Saúde. Portaria no 400 de 16 de novembro de 2009. Estabelece diretrizes nacionais para a atenção à saúde das pessoas ostomizadas no âmbito do sistema único de saúde, a serem observadas em todas as unidades federadas, respeitadas as competências das três esferas de gestão. Disponível em: http://bvsms.saude.gov.br/bvs/saudelegis/sas/2009/prt0400_16_11_2009.html

BRASIL. Ministério da Justiça. Lei Federal no 8069 de 13 de julho de 1990. Dispõe sobre o Estatuto da Criança e do Adolescente e dá outras providências. Disponível em: http://www.planalto.gov.br/ccivil_03/leis/18069.htm. Acesso em: 08 de outubro de 2016.

BRASIL. Ministério da Saúde. Conselho Nacional de Saúde. Resolução no 466 de 12 de dezembro de 2012. Diretrizes e normas regulamentadoras de pesquisas envolvendo seres humanos. Disponível em: http://www.conselho.saude.gov.br/resolucoes/2012/Reso466.pdf. 
BORGES, E.L.; RIBEIRO, M.S. Linha de cuidado da pessoa estomizada. Secretaria de Estado de Saúde de Minas Gerais. Belo Horizonte: SES-MG, 2015.

CARVALHO, W.A.F. Estomas em pediatria. Revista Estima, 2003; v.1, n.1. Disponível em: http://www.revistaestima.com.br/index.php/estima/article/view/121. Acesso em: 27 de outubro de 2016.

CENTRE FOR EVIDENCE-BASED MEDICINE (CEBM). Levels of evidence [Internet]. Oxford (UK): 2009. Disponível em: http://www.cebm.net/oxford-centre-evidence-basedmedicine-levels-evidence-march-2009/

CESARETTI, I.U.R.; PAULA, M.A.B. Demarcação do local para abertura da estomia. In: PAULA, M.A.B.; PAULA, P.R.; CESARETTI, I.U.R. Estomaterapia em foco e o cuidado especializado. São Caetano do Sul, SP: Editora Yendis, 2014.

CESARETTI, I.U.R.; SANTOS, V.L.C.G. Pele periestomia: prevenção e tratamento de lesão. In: PAULA, M.A.B.; PAULA, P.R.; CESARETTI, I.U.R. Estomaterapia em foco e o cuidado especializado. São Caetano do Sul, SP: Editora Yendis, 2014.

CESARETTI, I.U.R. et al. Cuidando de pessoas no período pré, trans e pós-operatório de cirurgias geradoras de estomias. In: SANTOS, V.L.C.G.; CESARETTI, I.U.R. Assistência em Estomaterapia: cuidando de pessoas com estomia. 2. ed. São Paulo: Editora Atheneu, 2015.

CESARETTI, I.U.R. et al. Tecnologia no cuidar de pessoas com estomia: a questão dos equipamentos e adjuvantes. In: SANTOS, V.L.C.G.; CESARETTI, I.U.R. Assistência em Estomaterapia: cuidando de pessoas com estomia. 2. ed. São Paulo: Editora Atheneu, 2015.

COLOGNA, A.J. Cistostomia. Medicina (Ribeirão Preto) 2011; 44(1): 57-62. Disponível em: http://revista.fmrp.usp.br/2011/vol44n1/Simp6_cistotomia.pdf. Acesso em: 05 de novembro de 2016.

CONSELHO FEDERAL DE ENFERMAGEM (COFEN). Parecer Técnico $\mathbf{n}^{\mathbf{0}}$ 06/2013. Disponível em: http://www.cofen.gov.br/wp-content/uploads/2014/10/PARECER-CTAS06_20131.pdf. Acesso em: 28 de outubro de 2016.

CONSELHO REGIONAL DE ENFERMAGEM DO PARANÁ (COREN-PR). Parecer Técnico $\mathbf{n}^{\mathbf{0}} \mathbf{0 1 0 / 2 0 1 3}$ Disponível em: http://www.corenpr.gov.br/portal/images/pareceres/PARTEC 13-010Troca_de_cateter_de_nefrostomia_por_Enfermeiro.pdf. Acesso em 05 de novembro de 2016. 
CONSELHO REGIONAL DE ENFERMAGEM DE SANTA CATARINA (COREN-SC). Parecer Técnico $\mathbf{n}^{\mathbf{0}} \mathbf{0 0 6 / 2 0 1 5}$. Disponível em: http://www.corensc.gov.br/wpcontent/uploads/2015/07/Parecer-006-2015-troca-de-c\%C3\%A2nula-de-traqueostomia-CTAlta-e-M\%C3\%A9dia-complexidade.pdf. Acesso em: 27 de outubro de 2016.

CONSELHO REGIONAL DE ENFERMAGEM DE SÃO PAULO (COREN-SP). Parecer Técnico $\quad \mathbf{n}^{\mathbf{0}} \quad \mathbf{0 4 1 / 2 0 1 2}$. Disponível em: http://portal.corensp.gov.br/sites/default/files/parecer_coren_sp_2012_41.pdf. Acesso em: 05 de novembro de 2016.

CRESWELL, J.W. Projeto de pesquisa: método qualitativo, quantitativo e misto. Tradução: Magda Lopes. 3. Ed. Porto Alegre: Artmed, 2010.

DINIZ, I.V. et al. Assistência de enfermagem aplicada à criança com estomia decorrente da doença de hirschsprung. Rev Enferm UFPE, Recife 2016; 10(3):1119-26.

DYER, R.B. et al. Percutaneous nephrostomy with extensions of the technique: step by step. Radiographics. 2002 may-jun; 22(3): 503-25. Disponível em: http://pubs.rsna.org/doi/pdf/10.1148/radiographics.22.3.g02ma19503.

EGITO, E.T.B.N. et al. Estado Nutricional de pacientes pediátricos ostomizados. Rev Paul Pediatr 2013; 31(1):58-64.

GAMBOA, N.S.G. Perspectivas do suporte da família e para a família de crianças com estomia. In: SANTOS, V.L.C.G.; CESARETTI, I.U.R. Assistência em Estomaterapia: cuidando de pessoas com estomia. 2. ed. São Paulo: Editora Atheneu, 2015.

GANONG, L.H. Integrative reviews of nursing research. Res Nurs Health, 1987; 10(1):1-11.

HABR-GAMA, A.; NETO, A.S.; ARAÚJO, S.E.A. Estomias intestinais: aspectos conceituais e técnicos. In: SANTOS, V.L.C.G.; CESARETTI, I.U.R. Assistência em Estomaterapia: cuidando de pessoas com estomia. 2. ed. São Paulo: Editora Atheneu, 2015.

HOCKENBERRY, M.J.; WILSON, D. Wong: fundamentos de enfermagem pediátrica. Tradução: Maria Inês Corrêa Nascimento et al. $8^{\text {a }}$ ed. Rio de Janeiro: Elsevier, 2011.

HORTENSE, F.T.P. Traqueostomia: cuidados. In: PAULA, M.A.B.; PAULA, P.R.; CESARETTI, I.U.R. Estomaterapia em foco e o cuidado especializado. São Caetano do Sul, SP: Editora Yendis, 2014. 
HULLEY, S.B. et al. Delineando a pesquisa clínica. 4. Ed. Tradução: André Garcia Islabão. Porto Alegre: Artmed, 2015.

ITAMOTO, C.H. et al. Indicações e complicações de traqueostomia em crianças. Braz J Otorhinolaryngol., 2010; 76(5): 326-31.

KAYO, C.M.M. et al. Cuidando de crianças com estomia. In: SANTOS, V.L.C.G.; CESARETTI, I.U.R. Assistência em Estomaterapia: cuidando de pessoas com estomia. 2. ed. São Paulo: Editora Atheneu, 2015.

KARIM, R. et al. Percutaneous nephrostomy by direct puncture technique: an observational study. Indian J Nephrol. 2010 Apr; 20(2): 84-88. Disponível em: https://www.ncbi.nlm.nih.gov/pmc/articles/PMC2931139/\#CIT4

LALANDE, L.F. Gastrostomias para nutrição enteral. Tradução: Elizabeth Dreyer. Editora Lince, 2011.

LEITE, N.S.L.; CUNHA, S.R. A família da criança dependente de tecnologia: aspectos fundamentais para a prática de enfermagem no ambiente hospitalar. Esc Anna Nery $R$ Enferm, 2007; 11(1): 92-7.

MABULA, J.B. et al. Hirschsprung's desease in children: a five year experience at a University teaching hospital in northwestern Tanzania. BMC Research Notes 2014; 7:410.

MACIEL, L.C. Estomias urinárias. In: PAULA, M.A.B.; PAULA, P.R.; CESARETTI, I.U.R. Estomaterapia em foco e o cuidado especializado. São Caetano do Sul, SP: Editora Yendis, 2014.

MALTA, M. et al. Iniciativa STROBE: subsídios para a comunicação de estudos observacionais. Rev Saúde Pública 2010; 44(3): 559-65.

MELO, M.C. Experiência materna com o filho estomizado. Dissertação de mestrado. Universidade de Brasília, Distrito Federal. Departamento de Enfermagem, Programa de Pósgraduação em enfermagem, 2010.

MELO, M.C.; KAMADA, I. Anomalia anorretal e cuidados maternos. Rev Bras Enferm, 2011, Brasília, jan-fev, 64(1): 176-179. 
MOENNE, K.B. Imagenes en anomalias anorectales. Rev Chil Radiol., 2003; Santiago, 9(1): 13-18.

MONTEIRO, S.N.C. Qualidade de vida: percepção de crianças e adolescentes estomizados e seus pais e/ou responsáveis. Dissertação de mestrado. Universidade de Brasília, Distrito Federal. Departamento de Enfermagem, Programa de Pós-graduação em Enfermagem, 2013.

MONTEIRO, S.N.C.; KAMADA, I.; SILVA, A.L.; SOUZA, T.C.R. Perfil de crianças e adolescentes estomizados atendidos em um hospital público do Distrito Federal. Rev Estima, 2014; 12(3): 23-32.

MONTEIRO, S.N.C.; MELO, M.C.; KAMADA, I. SILVA, A.L. Caracterização de cuidadores de crianças e adolescentes estomizados atendidos em serviço de reabilitação. Rev Estima, 2016; 14(2): 76-83.

MORAES, J.R.M.M.; CABRAL, I.E. A rede social de crianças com necessidades especiais em saúde na (in) visibilidade do cuidado de enfermagem. Rev Latino-Am Enfermagem, 2012; mar-abr, 20(2):[8 telas]. Disponível em: http://www.scielo.br/pdf/rlae/v20n2/pt_10.pdf.

MURAGAKI, W.H.; RAICHER, C.A. Estomias na criança. In: PAULA, M.A.B.; PAULA, P.R.; CESARETTI, I.U.R. Estomaterapia em foco e o cuidado especializado. São Caetano do Sul, SP: Editora Yendis, 2014.

NASCIMENTO, N.G.; BORGES, E.L.; DONOSO, M.T.V. Assistência de Enfermagem a pacientes gastrostomizados baseada em evidências. R. Enferm. Cent. O. Min., 2015; set/dez, 5(3): 1885-1897.

OLIVEIRA, J.Z.O.; MELANI, A.G.F. Colostomia perineal: indicações, técnicas e cuidados. In: SANTOS, V.L.C.G.; CESARETTI, I.U.R. Assistência em Estomaterapia: cuidando de pessoas com estomia. 2. ed. São Paulo: Editora Atheneu, 2015.

PAULA, M.A.B.; CESARETTI, I.U.R. Como cuidar de pessoas com estomias complicadas. In: PAULA, M.A.B.; PAULA, P.R.; CESARETTI, I.U.R. Estomaterapia em foco e o cuidado especializado. São Caetano do Sul, SP: Editora Yendis, 2014.

PAULA, M.A.B.; CESARETTI, I.U.R. Cuidando de pessoas com complicações nas estomias intestinais e pele periestomia. In: SANTOS, V.L.C.G.; CESARETTI, I.U.R. Assistência em Estomaterapia: cuidando de pessoas com estomia. 2. ed. São Paulo: Editora Atheneu, 2015 . 
PAULA, P.R.; MATOS, D. Complicações precoces e tardias nas estomias intestinais e pele periestoma. In: SANTOS, V.L.C.G.; CESARETTI, I.U.R. Assistência em Estomaterapia: cuidando de pessoas com estomia. 2. ed. São Paulo: Editora Atheneu, 2015.

PAULA, P.R.; SPERANZINI, M.B. Colostomias e ileostomia. In: PAULA, M.A.B.; PAULA, P.R.; CESARETTI, I.U.R. Estomaterapia em foco e o cuidado especializado. São Caetano do Sul, SP: Editora Yendis, 2014.

PELLEGRINO, D.M.S. Como cuidar de criança estomizada. In: PAULA, M.A.B.; PAULA, P.R.; CESARETTI, I.U.R. Estomaterapia em foco e o cuidado especializado. São Caetano do Sul, SP: Editora Yendis, 2014.

PEREIRA, M.G. Epidemiologia - teoria e prática. 6. ed. Rio de Janeiro: Guanabara Koogan, 2002.

PERSON, B. et al. The impact of preoperative stoma site making on the incidence of complications, quality of life and patient's independence. Dis Colon Rectum 2012; 55: 783787.

POGGETO, M.T. et al. Conhecimento profissional enfermeiro sobre a ileostomia na atenção básica. Rev. Min. Enferm., 2012; out/dez, 16(4): 502-508.

POLETTO, D.; GONÇALVES, M.I.; BARROS, M.T.T.; ANDERS, J.C.; MARTINS, M.L. A criança com estoma intestinal e sua família: implicações para o cuidado de enfermagem. Texto Contexto Enferm, Florianópolis, 2011, abril/junho, 20(2): 319-27.

PRIANTE, A.V.M.; CARDOSO, C.A. Esofagostomia, gastrostomia e traqueostomia. In: PAULA, M.A.B.; PAULA, P.R.; CESARETTI, I.U.R. Estomaterapia em foco e o cuidado especializado. São Caetano do Sul, SP: Editora Yendis, 2014.

REGISTERED NURSES' ASSOCIATION OF ONTARIO (RNAO). Ostomy care and management: clinical best practice guidelines. Toronto, Canada: Registered Nurses' Association of Ontario, 2009.

RICZ, H.M.A. et al. Traqueostomia. Medicina (Ribeirão Preto), 2011; 44(1): 63-9. Disponível em: http://revista.fmrp.usp.br/2011/vol44n1/Simp7_Traqueostomia.pdf. Acesso em: 27 de outubro de 2016.

ROCHA, J.J.R. Estomas intestinais (ileostomias e colostomias) e anastomoses intestinais. Medicina (Ribeirão Preto), 2011; 44(1): 51-56. 
ROCHA, R.F.C.; VELHOTE, M.C.P. Estomias na criança. In: SANTOS, V.L.C.G.; CESARETTI, I.U.R. Assistência em Estomaterapia: cuidando de pessoas com estomia. 2. ed. São Paulo: Editora Atheneu, 2015.

RODRIGUES, P. Estomias urinárias: aspectos conceituais e técnicos. In: SANTOS, V.L.C.G.; CESARETTI, I.U.R. Assistência em Estomaterapia: cuidando de pessoas com estomia. 2. ed. São Paulo: Editora Atheneu, 2015.

SAMPAIO, C.E.P. et al. Sentimento dos acompanhantes de crianças submetidas a procedimentos cirúrgicos: vivências no perioperatório. Rev Min Enferm, 2009; out/dez, 13(4): 558-564.

SANTOS, V.L.C.G.; CESARETTI, I.U.R. Evolução da Enfermagem em Estomaterapia no decorrer de sua história. In: SANTOS, V.L.C.G.; CESARETTI, I.U.R. Assistência em Estomaterapia: cuidando de pessoas com estomia. 2. ed. São Paulo: Editora Atheneu, 2015.

SANTOS, J.S. et al. Gastrostomia e jejunostomia: aspectos da evolução técnica e da ampliação das indicações. Medicina (Ribeirão Preto), 2011; 44(1): 39-50.

SANTOS, C.H.M. et al. Perfil do paciente ostomizado e complicações relacionadas ao estoma. Rev Bras Coloproct, 2007; 27(1): 16-19. Disponível em: http://www.scielo.br/pdf/rbc/v27n1/a02v27n1.pdf

SCHMIDT, F.M.Q.; HANATE, C. Complicações precoces e tardias nas estomias urinárias e pele periestomia. In: SANTOS, V.L.C.G.; CESARETTI, I.U.R. Assistência em Estomaterapia: cuidando de pessoas com estomia. 2. ed. São Paulo: Editora Atheneu, 2015.

SCHRAG, S.P. et al. Complications related to percutaneous endoscopic gastrostomy (PEG) tubes - A comprehensive clinical review. J Gastrointestin Liver Dis. 2007 dec; 16(4): 40718.

SECCANI, L.M.E.; RIBEIRO, P.A.; GRAVALOS, S.; PAULA, M.A.B.; VASCONCELLOS, A.C.L.P. Estomas intestinais em crianças: dificuldades relatadas pelos cuidadores familiares no processo de cuidar. Revista Estima, 2007, vol 5(3): 16-21.

SILVA, T.B. Traqueostomia em pacientes internados em Unidades de Terapia Intensiva de hospitais públicos do Distrito Federal: prevalência, indicações, tempo para realização do procedimento e técnica. Dissertação de mestrado. Universidade de Brasília, Distrito Federal. Programa de Pós-Graduação em Ciências e Tecnologias em Saúde, 2014. 
SILVEIRA, A.; NEVES, E.T. Crianças com necessidades especiais em saúde: cuidado familiar na preservação da vida. Cienc Cuid Saúde 2012; jan-mar, 11(1): 074-080.

SMELTZER, S.C. et al. Brunner \& Suddarth: tratado de enfermagem médico-cirúrgica. 12. ed. Rio de Janeiro: Guanabara Koogan, 2012.

STEIN, R.; SCHRÖDER, A.; THÜROFF, J.W. Bladder augmentation and urinary diversion in patients with neurogenic bladder: surgical considerations. J Pediatr Urol. 2012; 8(2):15361.

STENSTRÖM, P. et al. Appendicostomy in preschool children with anorectal malformation: successful early bowel management with a high frequency of minor complications. BioMEd Research International 2013; article ID 297084, 8 pages.

TEDDE, M.L et al. Traqueostomia: indicações, técnicas e cuidados no adulto. In: SANTOS, V.L.C.G.; CESARETTI, I.U.R. Assistência em Estomaterapia: cuidando de pessoas com estomia. 2. ed. São Paulo: Editora Atheneu, 2015.

TJADEN, N.E.B.; TRAINOR, P.A. The developmental etiology and pathogenesis of Hirschsprung disease. Transl Res. 2013 July; 162(1): 1-15.

URSI, ES. Prevenção de lesão de pele no perioperatório: revisão integrativa da literatura. Dissertação (mestrado). Ribeirão Preto: USP, 2005. Disponível em: http://www.teses.usp.br/teses/disponiveis/22/22132/tde-18072005-095456/pt-br.php

VALDES, A.G.; KAMADA, I.; CRISTO, R.C.; COSTA, S.B.; FAUSTINO, A.M. Experiência de crianças com estomias: estudo qualitativo. Rev Estima, 2010, vol 8(3): 19-26.

VIEIRA, F.S. Complicações de estoma intestinal e pele periestoma de pacientes em seguimento ambulatorial. Dissertação (mestrado). Programa de Pós-graduação: Enfermagem Fundamental. Ribeirão Preto: USP, 2014.

WOUND, OSTOMY AND CONTINENCE NURSES SOCIETY (WOCN). Pediatric Ostomy Care: Best Practice for Clinicians. Mount Laurel: NJ, WOCN Society, 2011.

WOUND, OSTOMY AND CONTINENCE NURSES SOCIETY (WOCN). WOCN and ASCRS position statement on preoperative stoma site making for patients undergoing colostomy or ileostomy surgery. Mount Laurel: NJ, WOCN Society, 2014. 
WOUND, OSTOMY AND CONTINENCE NURSES SOCIETY (WOCN). Pediatric ostomy complications: best practice for clinicians. Mount Laurel: NJ, WOCN Society, 2016.

YAMADA, B.F.A.; CESARETTI, I.U.R.; MARCONDES, M.G.S.G.; MORAIS, J.F.; PRADO, A.A.B. Ocorrência de complicações no estoma e pele periestoma: estudo retrospectivo. Rev Estima, 2003, vol 1(3): 16-24.

YAMADA, B.F.A. Pele - o manto protetor: higiene e hidratação. São Paulo: Andreoli, 2015. 
Apêndice e Anexos 


\section{APÊNDICE}

\section{APÊNDICE A}

Projeto: Complicação de estomias em crianças: frequência e fatores associados.

Pesquisadora: Talita Faraj Faria.

$\mathbf{N}^{\circ}$ do formulário:

\section{INSTRUMENTO DE COLETA DE DADOS}

Data:

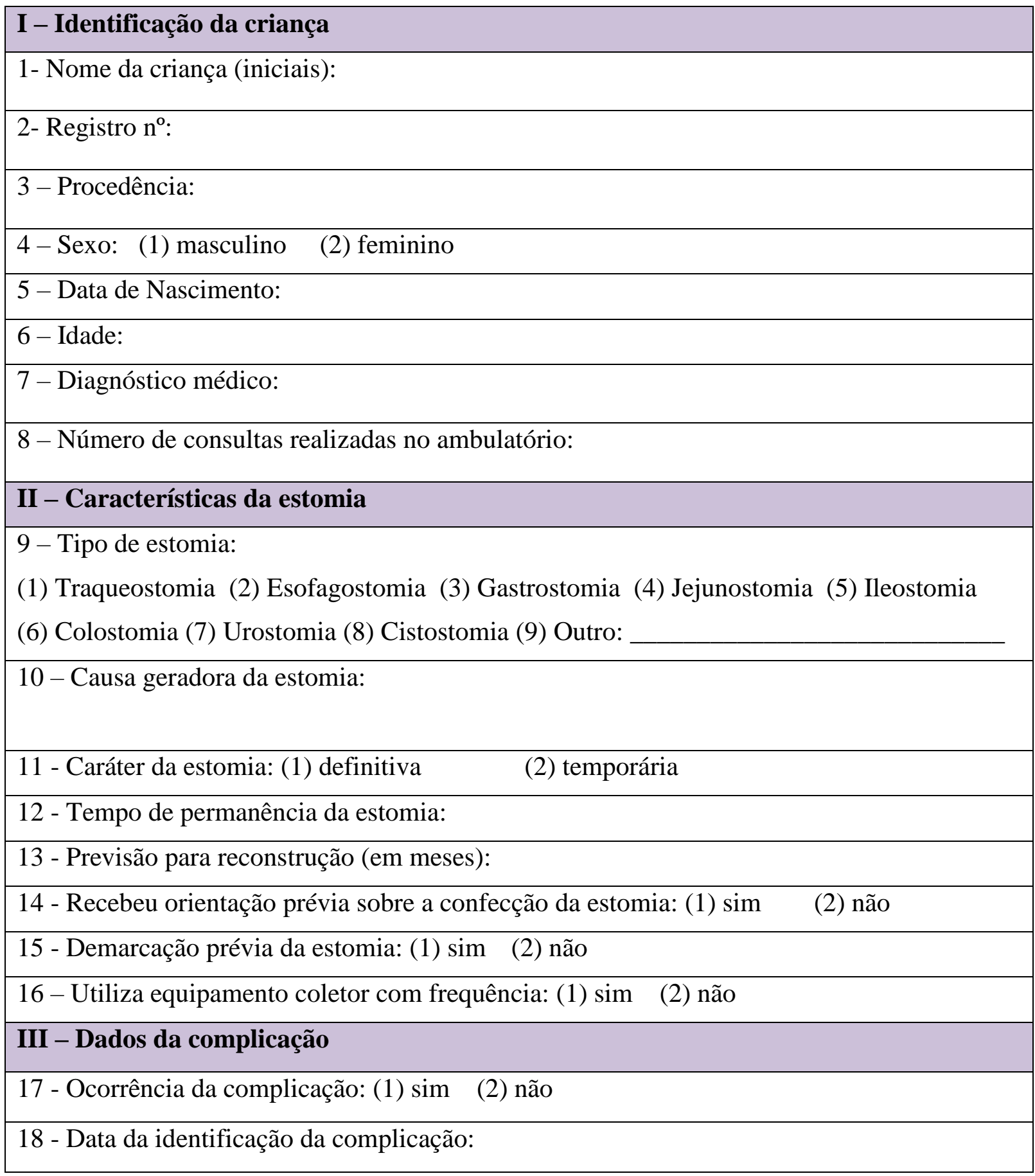


19 - Tipo de complicação:

(1) Necrose da estomia (2) Dermatite de contato (3) Dermatite alérgica (4) Dermatite por trauma (5) Retração (6) Hérnia paraestomia (7) Estenose (8) Prolapso de alça

(9) Separação cutaneomucosa (10) Outro:

20 - Provável fator que ocasionou a complicação

(1) Trauma (2) Contato com efluentes (3) Contato com agentes químicos

(4) hipersensibilidade ao equipamento coletor (5) aumento da pressão intra-abdominal

(6) Obesidade (7) Isquemia (8) Infecção (9) Outro:

21 - Tratamento empregado para resolução da complicação:

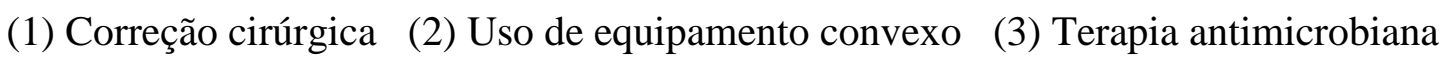

(4) Uso de barreira protetora de pele (5) Uso de cinta elástica (6) Redução digital

(7) Dilatação digital ou instrumental (8) Outro: 
ANEXOS

\begin{abstract}
ANEXO A
Projeto: "Complicação de estomias em crianças: frequência e fatores associados". Pesquisadora: Talita Faraj Faria.
\end{abstract}

\title{
Termo de Consentimento Livre e Esclarecido - TCLE
}

$\mathrm{O}(\mathrm{a})$ Senhor(a) está sendo convidado(a) a participar do projeto de mestrado intitulado “Complicações de estomias em crianças: frequência e fatores associados". O nosso objetivo é identificar com que frequência surgem as complicações de estomias nas crianças atendidas no ambulatório de atenção ao estomizado do Hospital Materno Infantil de Brasília.

Gostaríamos de contar com a sua colaboração, permitindo o acompanhamento seu(a) filho(a) durante o tempo em que ele for atendido neste setor, para observar se ele apresentará algum tipo de complicação. $\mathrm{O}$ (a) senhor(a) receberá todos os esclarecimentos necessários antes e no decorrer da pesquisa. Asseguramos que o nome de seu(a) filho(a) não aparecerá, sendo mantido o mais rigoroso sigilo através da omissão total de quaisquer informações que permitam identificá-lo(a), assim como será permitido o seu acesso aos dados obtidos por meio desta pesquisa a qualquer momento.

A participação de seu filho se dará através de um questionário que será preenchido pela pesquisadora, com informações obtidas por meio das anotações presentes no prontuário e da observação direta durante o atendimento dele(a) no ambulatório. Este trabalho não fornecerá nenhum tipo de pagamento ao participante. Se houver algum dano direto ou indireto decorrente da participação de seu(a) filho(a) na pesquisa, ele(a) poderá ser indenizado, obedecendo-se as disposições legais vigentes no Brasil. Caso concorde em deixá-lo(a) participar, o(a) senhor(a) deverá assinar as duas vias deste Termo de Consentimento Livre e Esclarecido, ficando uma via com o(a) senhor(a) e a outra com a pesquisadora.

Informamos que o(a) senhor(a) pode recusar que seu(a) filho(a) participe desta pesquisa ou pode desistir de participar a qualquer momento, sem nenhum prejuízo para o senhor(a) ou para o atendimento de seu(a) filho(a).

Os resultados da pesquisa serão divulgados no Ambulatório de Atenção ao Estomizado e na Universidade de Brasília (UnB), podendo ser publicados posteriormente em revistas científicas ou apresentado em congressos científicos. Os dados e materiais utilizados nesta pesquisa ficarão sob a guarda da pesquisadora por cinco anos e após este período serão destruídos. 
Se o(a) senhor(a) tiver qualquer dúvida em relação à pesquisa, por favor entre em contato com a pesquisadora Talita através do telefone: (61) 3879-1724 no período matutino; ou pelo endereço eletrônico: talitafaraj@gmail.com.

Este projeto foi Aprovado pelo Comitê de Ética em Pesquisa da SES/DF. Os direitos do sujeito da pesquisa e as dúvidas com relação à assinatura do TCLE podem ser sanadas através do telefone: (61) 3325-4955.

Desde já, agradecemos a sua participação!

$\mathrm{Eu}$,

declaro que recebi todas as informações sobre esta pesquisa e tirei todas as minhas dúvidas. Sei que a minha participação é por vontade própria e que posso desistir de participar a qualquer momento, sem que isso me traga qualquer problema ou prejuízo, por isso concordo em participar.

Brasília, Distrito Federal, de de 2016.

Assinatura do representante legal:

Talita Faraj Faria:

(Pesquisadora responsável) 


\section{ANEXO B \\ CHECKLIST STROBE STATEMENT}

STROBE Statement-checklist of items that should be included in reports of observational studies

\begin{tabular}{|c|c|c|}
\hline & $\begin{array}{c}\text { Item } \\
\text { No }\end{array}$ & Recommendation \\
\hline \multirow[t]{2}{*}{ Title and abstract } & \multirow[t]{2}{*}{1} & (a) Indicate the study's design with a commonly used term in the title or the abstract \\
\hline & & $\begin{array}{l}\text { (b) Provide in the abstract an informative and balanced summary of what was done } \\
\text { and what was found }\end{array}$ \\
\hline
\end{tabular}

Introduction

\begin{tabular}{lll}
\hline Background/rationale & 2 & Explain the scientific background and rationale for the investigation being reported
\end{tabular}

\begin{tabular}{lll}
\hline Objectives & 3 & State specific objectives, including any prespecified hypotheses \\
\hline
\end{tabular}

Methods

\begin{tabular}{lll}
\hline Study design & 4 & Present key elements of study design early in the paper \\
\hline Setting & 5 & $\begin{array}{l}\text { Describe the setting, locations, and relevant dates, including periods of recruitment, } \\
\text { exposure, follow-up, and data collection }\end{array}$
\end{tabular}
exposure, follow-up, and data collection

Participants 6 (a) Cohort study - Give the eligibility criteria, and the sources and methods of selection of participants. Describe methods of follow-up

Case-control study - Give the eligibility criteria, and the sources and methods of case ascertainment and control selection. Give the rationale for the choice of cases and controls

Cross-sectional study - Give the eligibility criteria, and the sources and methods of selection of participants

(b) Cohort study-For matched studies, give matching criteria and number of exposed and unexposed

Case-control study-For matched studies, give matching criteria and the number of controls per case

\begin{tabular}{|c|c|c|}
\hline Variables & 7 & $\begin{array}{l}\text { Clearly define all outcomes, exposures, predictors, potential confounders, and effect } \\
\text { modifiers. Give diagnostic criteria, if applicable }\end{array}$ \\
\hline $\begin{array}{l}\text { Data sources/ } \\
\text { measurement }\end{array}$ & $8^{*}$ & $\begin{array}{l}\text { For each variable of interest, give sources of data and details of methods of } \\
\text { assessment (measurement). Describe comparability of assessment methods if there } \\
\text { is more than one group }\end{array}$ \\
\hline Bias & 9 & Describe any efforts to address potential sources of bias \\
\hline Study size & 10 & Explain how the study size was arrived at \\
\hline Quantitative variables & 11 & $\begin{array}{l}\text { Explain how quantitative variables were handled in the analyses. If applicable, } \\
\text { describe which groupings were chosen and why }\end{array}$ \\
\hline \multirow[t]{6}{*}{ Statistical methods } & \multirow[t]{6}{*}{12} & (a) Describe all statistical methods, including those used to control for confounding \\
\hline & & (b) Describe any methods used to examine subgroups and interactions \\
\hline & & (c) Explain how missing data were addressed \\
\hline & & (d) Cohort study - If applicable, explain how loss to follow-up was addressed \\
\hline & & $\begin{array}{l}\text { Case-control study-If applicable, explain how matching of cases and controls was } \\
\text { addressed }\end{array}$ \\
\hline & & $\begin{array}{l}\text { Cross-sectional study-If applicable, describe analytical methods taking account of } \\
\text { sampling strategy }\end{array}$ \\
\hline
\end{tabular}




\begin{tabular}{|c|c|c|}
\hline sults & & \\
\hline \multirow[t]{3}{*}{ Participants } & \multirow[t]{3}{*}{$13^{*}$} & $\begin{array}{l}\text { (a) Report numbers of individuals at each stage of study - eg numbers potentially eligible, } \\
\text { examined for eligibility, confirmed eligible, included in the study, completing follow-up, and } \\
\text { analysed }\end{array}$ \\
\hline & & (b) Give reasons for non-participation at each stage \\
\hline & & (c) Consider use of a flow diagram \\
\hline \multirow[t]{3}{*}{$\begin{array}{l}\text { Descriptive } \\
\text { data }\end{array}$} & \multirow[t]{3}{*}{$14^{*}$} & $\begin{array}{l}\text { (a) Give characteristics of study participants (eg demographic, clinical, social) and information } \\
\text { on exposures and potential confounders }\end{array}$ \\
\hline & & (b) Indicate number of participants with missing data for each variable of interest \\
\hline & & (c) Cohort study-Summarise follow-up time (eg, average and total amount) \\
\hline \multirow[t]{3}{*}{ Outcome data } & \multirow[t]{3}{*}{$15^{*}$} & Cohort study-Report numbers of outcome events or summary measures over time \\
\hline & & $\begin{array}{l}\text { Case-control study-Report numbers in each exposure category, or summary measures of } \\
\text { exposure }\end{array}$ \\
\hline & & Cross-sectional study-Report numbers of outcome events or summary measures \\
\hline \multirow[t]{3}{*}{ Main results } & \multirow[t]{3}{*}{16} & $\begin{array}{l}\text { (a) Give unadjusted estimates and, if applicable, confounder-adjusted estimates and their } \\
\text { precision (eg, } 95 \% \text { confidence interval). Make clear which confounders were adjusted for and } \\
\text { why they were included }\end{array}$ \\
\hline & & (b) Report category boundaries when continuous variables were categorized \\
\hline & & $\begin{array}{l}\text { (c) If relevant, consider translating estimates of relative risk into absolute risk for a meaningful } \\
\text { time period }\end{array}$ \\
\hline Other analyses & 17 & $\begin{array}{l}\text { Report other analyses done-eg analyses of subgroups and interactions, and sensitivity } \\
\text { analyses }\end{array}$ \\
\hline \multicolumn{3}{|l|}{ Discussion } \\
\hline Key results & 18 & Summarise key results with reference to study objectives \\
\hline Limitations & 19 & $\begin{array}{l}\text { Discuss limitations of the study, taking into account sources of potential bias or imprecision. } \\
\text { Discuss both direction and magnitude of any potential bias }\end{array}$ \\
\hline Interpretation & 20 & $\begin{array}{l}\text { Give a cautious overall interpretation of results considering objectives, limitations, multiplicity } \\
\text { of analyses, results from similar studies, and other relevant evidence }\end{array}$ \\
\hline Generalisability & 21 & Discuss the generalisability (external validity) of the study results \\
\hline \multicolumn{3}{|c|}{ Other information } \\
\hline Funding & 22 & $\begin{array}{l}\text { Give the source of funding and the role of the funders for the present study and, if applicable, } \\
\text { for the original study on which the present article is based }\end{array}$ \\
\hline
\end{tabular}

*Give information separately for cases and controls in case-control studies and, if applicable, for exposed and unexposed groups in cohort and cross-sectional studies.

Note: An Explanation and Elaboration article discusses each checklist item and gives methodological background and published examples of transparent reporting. The STROBE checklist is best used in conjunction with this article (freely available on the Web sites of PLoS Medicine at http://www.plosmedicine.org/, Annals of Internal Medicine at http://www.annals.org/, and Epidemiology at http://www.epidem.com/). Information on the STROBE Initiative is available at www.strobe-statement.org. 


\section{ANEXO C \\ PARECER DE APROVAÇÃO DO COMITÊ DE ÉTICA EM PESQUISA (CEP/FEPECS)}

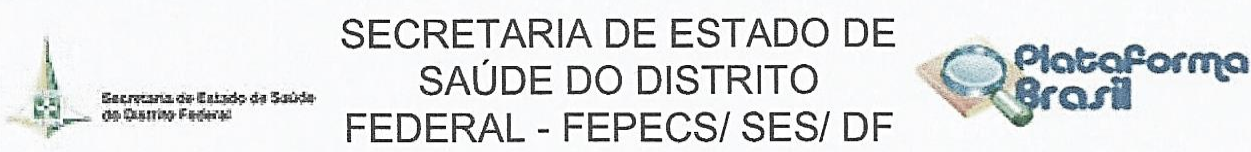

\section{PARECER CONSUBSTANCIADO DO CEP}

\section{DADOS DO PROJETO DE PESQUISA}

Título da Pesquisa: Complicações de estomias em crianças: frequência e fatores associados

Pesquisador: Talita Faraj Faria

Área Temática:

Versão: 1

CAAE: 52299215.0 .0000 .5553

Instituição Proponente: Hospital Materno Infantil de Brasilia - HMIB

Patrocinador Principal: Financiamento Próprio

\section{DADOS DO PARECER}

Número do Parecer: 1.399 .909

Apresentação do Projeto:

"O processo de confecção da estomia na criança gera impacto em seu cotidiano e no de seus familiares, pois afeta sua integridade corporal, assim como sua capacidade funcional, convívio social e sua qualidade de vida. Apesar de a confecção do estoma ser considerada um procedimento cirúrgico simples e comumente realizado, geralmente surgem complicações que, na maioria das vezes podem ser evitadas. Trata-se de um estudo

quantitativo, descritivo, de caráter prospectivo, que será realizado no período de janeiro a junho de 2016 no Ambulatório de Atenção ao Estomizado do Hospital Materno Infantil de Brasília, Distrito Federal. A análise estatística será realizada com a utilização do programa Statistical Package for the Social Sciences® (SPSS), versão 23.0, onde as variáveis categóricas serão descritas por meio de frequência absoluta e relativa e as variáveis quantitativas por meio da média e desvio padrão. Espera-se que os dados obtidos a partir desta pesquisa possam ser utilizados para melhorar o atendimento das crianças estomizadas, subsidiando o planejamento das ações dos profissionais de saúde, a fim de evitar elou diminuir a ocorrência das complicações."

Objetivo da Pesquisa:

"Objetivo Primário:

Estudar a ocorrência de complicações de estomias em crianças atendidas no Ambulatório de Atenção ao Estomizado do Hospital Materno Infantil de Brasilia (HMIB).

Endereço: SMHN 2 Qd 501 BLOCO A - FEPECS

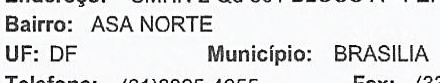


Faculdade de Ciências da Saúde Programa de Pós-graduação em Enfermagem

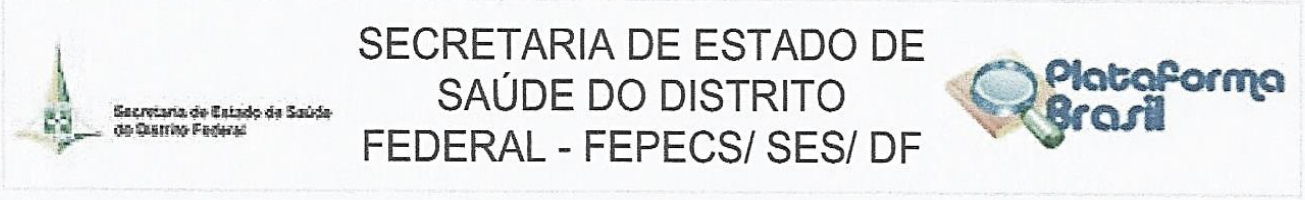

Continuação do Parecer: 1.399 .909

Objetivo Secundário:

Caracterizar o perfil sociodemográfico e clínico das crianças atendidas no Ambulatório de Atenção ao Estomizado do HMIB; Verificar a incidência de complicações de estomias nas crianças atendidas no ambulatório; Verificar o tipo de complicações existentes no estoma e pele periestoma das crianças atendidas, além do tratamento empregado para resolução do problema."

Avaliação dos Riscos e Benefícios:

"Riscos:

Considerando que toda pesquisa com seres humanos envolve riscos em tipos e gradações variadas, a pesquisadora e as instituições envolvidas neste estudo se responsabilizam por prestar assistência imediata e integral aos participantes da pesquisa caso estes venham a sofrer danos e/ou complicações decorrentes do estudo, tendo sido ou não previstos no Termo de Consentimento Livre e Esclarecido (TCLE). Comprometemo-nos ainda a garantir que os danos previsiveis sejam evitados buscando, entre outros, que os benefícios esperados sempre prevaleçam sobre os riscos elou desconfortos previsiveis (BRASIL, 2012). Beneficios:

A confecção de uma estomia na infância pode gerar mudanças significativas na vida da criança e de seus pais e/ou responsáveis, repercutindo no seu desenvolvimento biopsicossocial, além de provocar mudanças no seu estilo de vida, sendo necessária a criação de estratégias para enfrentamento desta condição (VALDES et al, 2010). Deste modo, espera-se que os objetivos deste estudo sejam alcançados e que seja possivel

conhecer a incidência das complicações de estomias em crianças de zero a 12 anos incompletos, assim como o tipo de complicação e sua localização, além da terapêutica implementada e dos dados sociodemográficos e clínicos das crianças estudadas. Os resultados obtidos poderão trazer benefícios em termos de conhecimento para melhorar o atendimento relativo às crianças estomizadas, subsidiando o planejamento das ações

dos profissionais de saúde a fim de evitar e/ou diminuir a ocorrência dessas complicações, além de contribuir para redução dos gastos que envolvem o seu tratamento e, consequentemente, melhorando a qualidade de vida dessas crianças."

\section{Comentários e Considerações sobre a Pesquisa:}

"Trata-se de um estudo quantitativo, descritivo, de caráter prospectivo que será realizado no Ambulatório de Atenção ao Estomizado do Hospital Materno Infantil de Brasilia (HMIB) no periodo de janeiro a junho de 2016. O Programa de Atenção ao Estomizado do HMIB atende crianças e/ou adolescentes estomizados desde 2002. Atualmente, funciona nas quintas-feiras no período

Endereço: SMHN 2 Qd 501 BLOCO A - FEPECS

Bairro: ASA NORTE

UF: DF Municipio: BRASILIA

Telefone: (61)3325-4955 Fax: (33)3325-4955 E-mail: comitedeetica.secretaria@gmail.com 


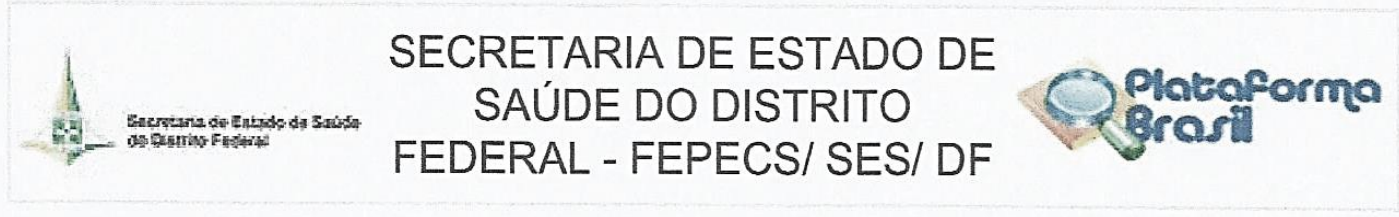

Continuação do Parecer: 1.399 .909

matutino (das $7 \mathrm{~h}$ às $11 \mathrm{~h}$ ) com uma média de 18 a 25 consultas mensais. A seleção da amostra será constituída por conveniência, ou seja, não-aleatória, composta pelas crianças atendidas no referido ambulatório. Para a coleta de dados será utilizado um instrumento que foi elaborado especificamente para esta

finalidade, visando a caracterização da população do estudo e a identificação das complicações de estomias. Será realizado estudo piloto para verificar a adequação do instrumento e realizar ajustes, caso seja necessário. Serão levantados dados sociodemográficos e clínicos das crianças por meio de análise dos prontuários, cujas variáveis são sexo, procedência, data de nascimento, idade, diagnóstico médico e número de consultas realizadas no ambulatório. Os dados referentes às estomias, às complicações e os fatores associados ao seu surgimento serão levantados também por meio da análise de prontuários e por meio da observação direta das crianças durante as consultas, cujas variáveis são: tipo de estomia, causa geradora da estomia, tempo de permanência, caráter da estomia (definitiva ou temporária), previsão para reconstrução (em meses), demarcação

prévia, utilização de equipamento coletor, ocorrência de complicação, tipo de complicação, provável fator que ocasionou a complicação, tratamento empregado para resolução da complicação, entre outros."

Considerações sobre os Termos de apresentação obrigatória:

Foram apresentados adequadamente os termos:

- Folha de Rosto

- Termo de Concordância

- Projeto de pesquisa completo contendo cronograma e orçamento da pesquisa

- Reflexão sobre os Riscos e Benefícios da Pesquisa, a luz da Resolução CNS/MS 466/12

- Currículo vitae da pesquisadora principal e demais pesquisadores citados no projeto

Recomendações:

Conclusões ou Pendências e Lista de Inadequações:

Projeto aprovado.

Relembramos a necessidade de enviar a este CEP/FEPECS os relatórios parciais e final, bem como realizar a aplicação da pesquisa na forma como foi aprovada por este CEP.

Considerações Finais a critério do CEP:

Este parecer foi elaborado baseado nos documentos abaixo relacionados:

Endereço: SMHN 2 Qd 501 BLOCO A - FEPECS

Bairro: ASA NORTE

UF: DF Município: BRASILIA

Telefone: (61)3325-4955 Fax: (33)3325-4955_E-mail: comitedeetica.secretaria@gmail.com 
Faculdade de Ciências da Saúde

Programa de Pós-graduação em Enfermagem

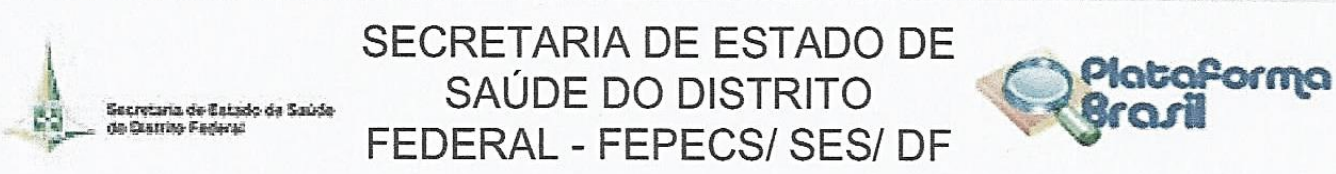

Continuação do Parecer: 1.399.909

\begin{tabular}{|c|c|c|c|c|}
\hline Tipo Documento & Arquivo & Postagem & Autor & Situação \\
\hline $\begin{array}{l}\text { Informações Básicas } \\
\text { do Projeto }\end{array}$ & $\begin{array}{l}\text { PB_INFORMAÇÕES_BÁSICAS_DO_P } \\
\text { ROJETO 636733.pdf }\end{array}$ & $\begin{array}{l}09 / 12 / 2015 \\
15: 35: 11\end{array}$ & & Aceito \\
\hline $\begin{array}{l}\text { TCLE / Termos de } \\
\text { Assentimento / } \\
\text { Justificativa de } \\
\text { Ausência }\end{array}$ & TCLE.docx & $\begin{array}{l}09 / 12 / 2015 \\
15: 31: 23\end{array}$ & Talita Faraj Faria & Aceito \\
\hline $\begin{array}{l}\text { Projeto Detalhado / } \\
\text { Brochura } \\
\text { Investigador }\end{array}$ & Projeto_de_Pesquisa_TalitaFaraj.docx & $\begin{array}{c}09 / 12 / 2015 \\
15: 28: 39\end{array}$ & Talita Faraj Faria & Aceito \\
\hline Outros & Lattes_IvoneKamada.pdf & $\begin{array}{l}09 / 12 / 2015 \\
15: 24: 42\end{array}$ & Talita Faraj Faria & Aceito \\
\hline Outros & Lattes_TalitaFaraj.pdf & $\begin{array}{c}09 / 12 / 2015 \\
15: 24: 00\end{array}$ & Talita Faraj Faria & Aceito \\
\hline Outros & termo_de_concordancia.pdf & $\begin{array}{c}09 / 12 / 2015 \\
15: 22: 57\end{array}$ & Talita Faraj Faria & Aceito \\
\hline Folha de Rosto & Folha_de_Rosto.pdf & $\begin{array}{c}09 / 12 / 2015 \\
15: 20: 30\end{array}$ & Talita Faraj Faria & Aceito \\
\hline
\end{tabular}

Situação do Parecer:

Aprovado

Necessita Apreciação da CONEP:

Não

BRASILIA, 01 de Fevereiro de 2016

\begin{tabular}{c}
\hline Assinado por: \\
Helio Bergo \\
(Coordenador)
\end{tabular}

Endereço: SMHN 2 Qd 501 BLOCO A - FEPECS

Bairro: ASA NORTE

UF: DF Município: BRASILIA

CEP: $70.710-904$

Telefone: (61)3325-4955 Fax: (33)3325-4955 E-mail: comitedeetica.secretaria@gmail.com 